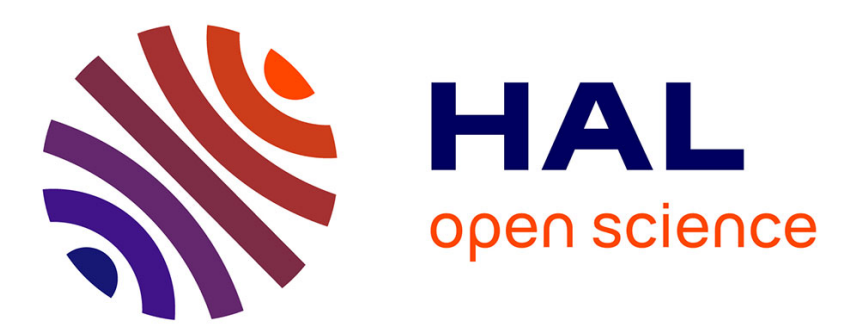

\title{
Nanomedicines for the delivery of glucocorticoids and nucleic acids as potential alternatives in the treatment of rheumatoid arthritis
}

Zhibo Yu, Franceline Reynaud, Mathilde Lorscheider, Nicolas Tsapis, Elias Fattal

\section{To cite this version:}

Zhibo Yu, Franceline Reynaud, Mathilde Lorscheider, Nicolas Tsapis, Elias Fattal. Nanomedicines for the delivery of glucocorticoids and nucleic acids as potential alternatives in the treatment of rheumatoid arthritis. Wiley Interdisciplinary Reviews: Nanomedicine and Nanobiotechnology, In press, 10.1002/wnan.1630. hal-02893397

\section{HAL Id: hal-02893397 \\ https://hal.science/hal-02893397}

Submitted on 8 Jul 2020

HAL is a multi-disciplinary open access archive for the deposit and dissemination of scientific research documents, whether they are published or not. The documents may come from teaching and research institutions in France or abroad, or from public or private research centers.
L'archive ouverte pluridisciplinaire HAL, est destinée au dépôt et à la diffusion de documents scientifiques de niveau recherche, publiés ou non, émanant des établissements d'enseignement et de recherche français ou étrangers, des laboratoires publics ou privés. 


\title{
Nanomedicines for the delivery of glucocorticoids and nucleic acids as potential alternatives in the treatment of rheumatoid arthritis
}

\author{
Zhibo Yu ${ }^{\mathrm{a}}$, Franceline Reynaud ${ }^{\mathrm{a}, \mathrm{b}}$, Mathilde Lorscheider ${ }^{\mathrm{a}}$, Nicolas Tsapis ${ }^{\mathrm{a}}$, Elias Fattal ${ }^{\mathrm{a}}$ \\ ${ }^{a}$ Institut Galien Paris-Sud, CNRS, Univ. Paris-Sud, Univ. Paris-Saclay, 92290 \\ Châtenay-Malabry, France \\ ${ }^{b}$ School of Pharmacy, Federal University of Rio de Janeiro, 21944-59 Rio de Janeiro, Brazil \\ *Corresponding author: \\ Elias Fattal, Ph.D \\ Université Paris-Saclay \\ Institut Galien Paris-Sud \\ UMR CNRS 8612 \\ 5 Rue Jean-Baptiste Clément \\ 92290 Châtenay-Malabry \\ France
}




\section{Graphical abstract}

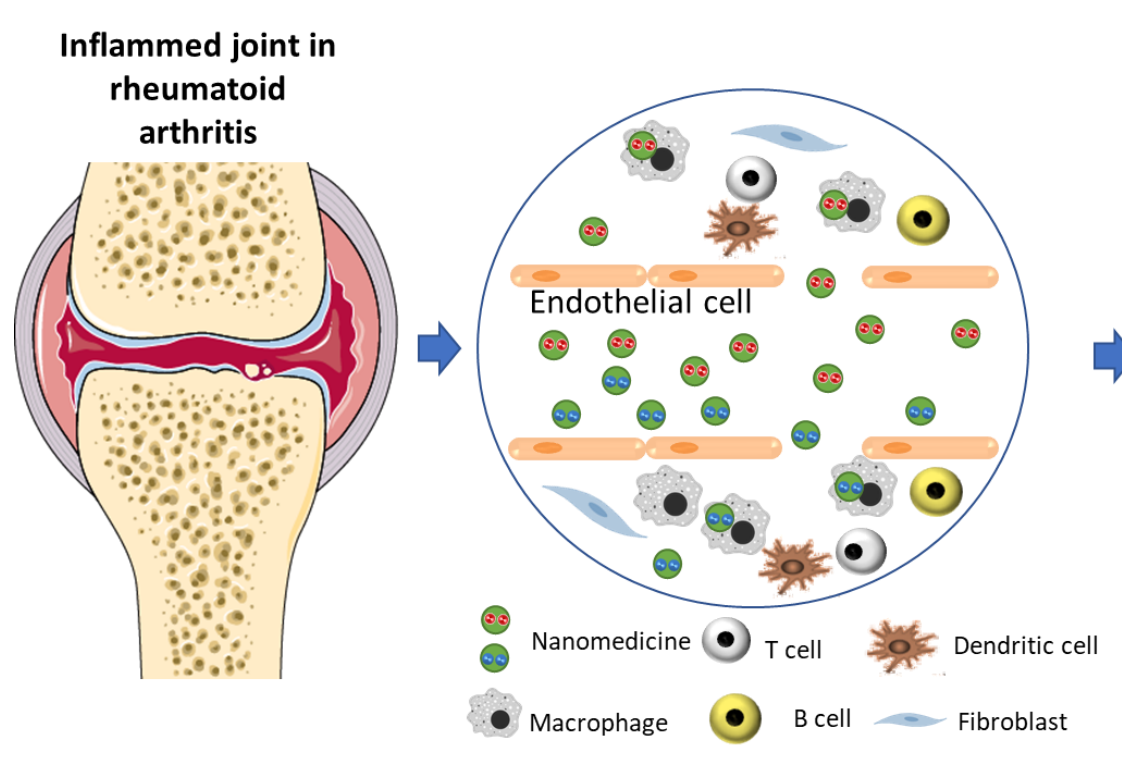

Blood Vessels

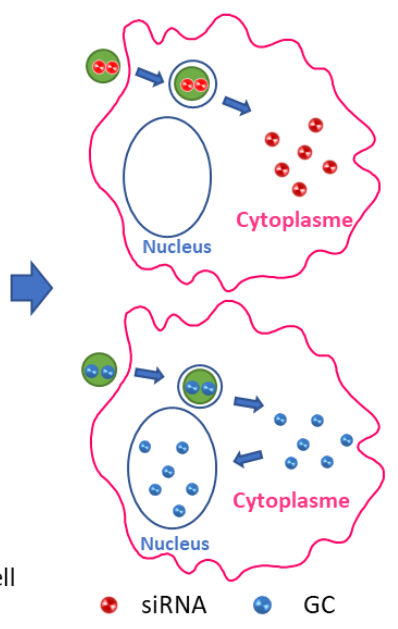

Target cell 


\begin{abstract}
Rheumatoid arthritis (RA) is a chronic autoimmune disease that affects 0.5 to $1 \%$ of the world population. Current treatments include on one hand non-steroidal anti-inflammatory drugs and glucocorticoids (GCs) for treating pain and on the other hand disease-modifying anti-rheumatic drugs such as methotrexate, Janus kinase inhibitors or biologics such as antibodies targeting mainly cytokine expression. More recently, nucleic acids such as siRNA, miRNA or anti-miRNA have shown strong potentialities for the treatment of RA. This review discusses the way nanomedicines can target GCs and nucleic acids to inflammatory sites, increase drug penetration within inflammatory cells, achieve better subcellular distribution and finally protect drugs against degradation. For GCs such a targeting effect would allow the treatment to be more effective at lower doses and to reduce the administration frequency as well as to induce much fewer side-effects. In the case of nucleic acids, particularly siRNA, knocking down proteins involved in RA, could importantly be facilitated using nanomedicines. Finally, the combination of both siRNA and GCs in the same carrier allowed for the same cell to target both the GCs receptor as well as any other signaling pathway involved in RA. Nanomedicines appear to be very promising for the delivery of conventional and novel drugs in RA therapeutics.
\end{abstract}

Key-words: nanomedicines, rheumatoid arthritis, small interfering RNA, glucocorticoids 


\section{Introduction}

Among inflammatory diseases of autoimmune origin, rheumatoid arthritis (RA) is the most common inflammatory rheumatism (Firestein, 1999). It is defined as a chronic, autoimmune disease that affects all types of patients with a strong prevalence in 60-80 years old women and a female: male ratio of 3:1 (Scott, Wolfe, \& Huizinga, 2010; Tobon, Youinou, \& Saraux, 2010). RA affects 0.5 to $1 \%$ of the world population with a higher incidence and prevalence in North America as well as in Northern Europe compared to Southern Europe and developing countries (Scott et al., 2010; Tobon et al., 2010). RA remains a serious inflammatory disease that is the subject of much research to improve existing therapies. Currently available are treatment of pain-related arthritis which includes non-steroidal anti-inflammatory drugs, glucocorticoids (GCs), and disease-modifying anti-rheumatic drugs (DMARDs) such as methotrexate or targeted DMARDs, such as Janus kinase inhibitors or of biological origin (biological DMARDs such as tumour necrosis factor TNF $\alpha$ inhibitors, costimulation modifiers, interleukin-6-inhibitors and B-cell depleting drugs) (Chatzidionysiou et al., 2017). Once administered, these drugs distribute not only in the diseased area but also in healthy tissues, leading to side-effects. More recently, several reports have described the possibility of inhibiting cytokine expression using small interfering RNA (siRNAs), microRNA (miRNAs) or anti-microRNA (anti-miRNAs) but none of these latest drugs is on the market for treating RA (Apparailly \& Jorgensen, 2013; Evangelatos, Fragoulis, Koulouri, \& Lambrou, 2019; Rai et al., 2019).

Nanomedicines are taking advantage of the specific physiopathology of inflamed tissues, specifically of a vascular enhanced permeability effect to address encapsulated molecules to the tissue of interest by passive diffusion in the diseased area (Dolati et al., 2016; Pham, 2011). Accumulation of nanomedicines in inflamed joints could, therefore, improve anti-inflammatory activity while avoiding the administration of high doses and thus reducing off-target effects of several drugs (Lorscheider, Tsapis, ur-Rehman, et al., 2019; Ozbakir, Crielaard, Metselaar, Storm, \& Lammers, 2014; Pirmardvand Chegini, Varshosaz, \& Taymouri, 2018; Xiao, Tang, Lv, Lin, \& Chen, 2019; M. Yang, Feng, Ding, Chang, \& Chen, 2017). Considering these characteristics, non-targeted drugs used in rheumatoid arthritis such as GCs and nucleic acids are good candidates for nanomedicine-based delivery. While GCs have numerous undesirable effects due to their distribution throughout the body and the ubiquitous presence of GC-receptors, nucleic acids such as siRNAs, miRNAs or anti-miRNA display poor stability in biological fluids as well as low cellular penetration. The present review is aiming to summarize the impact of the formulation of both GCs and nucleic acids in the nanoparticulate form in terms of pharmacokinetics, biodistribution and therapeutic efficacy in RA.

\section{Physiopathology of rheumatoid arthritis}

Among auto-immune inflammatory diseases, RA is the most frequent. It is an autoimmune connective tissue disease defined by a possible attack of many tissues including the connective tissues, arthralgias as well as an alteration of the general state. The biological signs correspond to an inflammatory syndrome accompanied by the production of specific auto-reactive antibodies 
(Y. W. Song \& Kang, 2009). RA evolves by outbreaks due to inflammation of the synovial membrane of the joints, resulting in joint destruction and pain. Patients generally experience a decrease in their quality of life, potentially a disability and a reduction in life expectancy of about 10 years. Despite a diminution in RA mortality over the last 50 years due to new therapies, it remains higher than the mortality of the general population (Dadoun et al., 2013). The presence of genetic, hormonal, and environmental factors results in the activation of innate and acquired immunity and leads to a disproportionate, persistent and uncontrolled inflammatory response of the synovial membrane (Gibofsky, 2014).

The physiopathology of RA can be described in three phases: i) the triggering of the autoimmune reaction ii) the inflammation and iii) the osteocartilaginous destruction. A major component of genetic susceptibility to RA can be explained by the inheritance of the HLA-DRB1 allele which starts the autoimmune reaction (van Drongelen \& Holoshitz, 2017). Particularly, the expression of the HLADRB $1 * 01$ and $* 04$ alleles corresponding to the shared epitope induces the presence of the HLA class II molecule on the surface of antigen-presenting cells recognizing the antigens responsible for the immune reaction of RA (Figure 1) (Roudier, 2000). After binding the antigen, the dendritic cells (DCs), migrate into lymphoid organs such as the thymus to activate naive $T$ cells. DCs are partly responsible for the chronicity of inflammation because their poor regulation during RA results in a prolonged presentation of the responsible antigen and therefore a sustained immune reaction.

Antigenic presentation to naive $\mathrm{T}$ cells necessarily requires co-stimulation. Firstly, the HLA molecule of the DCs presents the antigen to the lymphocyte via the T Cell Receptor (TCR) (Figure 1), secondly, the CD80 or B7 surface molecules of the DCs stimulate the CD28 receptor of the naive lymphocyte (Figure 1). Following this presentation, the $\mathrm{T}$ cells are activated and, depending on the cytokine environment produced by the DCs, differentiate into Th1 lymphocytes induced by the cytokines interleukin IL-12 and IL-18 (Figure 1) or in Th17 lymphocytes, if the environment is rich in IL-23 (Figure 1) (Gierut, Perlman, \& Pope, 2010). It is known that proinflammatory Th1 lymphocytes, as well as the Th17, play a major role in inflammation in RA (Gibofsky, 2014; X. Li et al., 2010).

After activation, the Th1 lymphocytes express on their surface adhesion molecules, L-selectins, which allow diapedesis, migration through the vascular endothelium to the inflammatory site through adhesion to endothelial cells which also present adhesion molecules named E-selectins (Tarrant \& Patel, 2006). Th1 activate antigen-presenting cells (APCs) that are macrophages, dendritic cells and B lymphocytes, which generates positive feedback and therefore an amplification of the immune response. Activated B cells act as APCs and present the responsible antigen to naive $\mathrm{T}$ cells, thereby maintaining inflammation. In addition, $\mathrm{B}$ cells produce antibodies. Among them, the rheumatoid factor (RF) that was first described and then a number of other autoantibodies that have been discovered in RA patients among which the anticitrullinated protein antibodies (ACPAs) (Figure 1). Both RF and ACPAs have been recognized for their acceptable sensitivities and specificities, and prognostic values (Y. W. Song $\&$ Kang, 2009). These autoantibodies form circulating immune complexes that deposit on the wall of blood vessels and may lead to vasculitis. In addition, immune complexes promote the 
production of pro-inflammatory cytokines that maintain the synovial pannus (Figure 1).

It is recognized that $\mathrm{T}$ cells are essential in triggering inflammation and immune response, but mainly synoviocytes play a major role in maintaining local joint inflammation. Indeed, the $\mathrm{T}$ cells activate the synoviocytes by direct contact as well as by the production of pro-inflammatory cytokines such as interferon- $\gamma$ (IFN $\gamma$ ), IL-2 and IL-17 (Figure 1). The synoviocytes constitute the majority of the cell population of the border layer of the synovial membrane. There are two types of synoviocytes: macrophage synoviocytes, commonly called macrophages, and fibroblast-like synoviocytes (Iwanaga, Shikichi, Kitamura, Yanase, \& Nozawa-Inoue, 2000). Macrophage synoviocytes synthesize leukotrienes, prostaglandins, enzymes and free radicals responsible for both maintenances of inflammation and osteocartilaginous destruction. In addition, these macrophages produce pro-inflammatory cytokines including IL-1 $\beta$, Tumor Necrosis Factor $\alpha$ (TNF $\alpha$ ) and IL-6 (Figure 1). IL-1 $\beta$ and TNF $\alpha$ are major actors in the inflammatory mechanism (Brennan, Jackson, Chantry, Maini, \& Feldmann, 1989). IL-6 is an interesting cytokine because it has pro and anti-inflammatory properties. It is involved in the immune response of RA but its role is still not completely understood. Many other cytokines are involved in the physiopathology of RA (Mateen, Zafar, Moin, Khan, \& Zubair, 2016; McInnes \& Schett, 2007). These cytokines induce the synthesis of other pro-inflammatory cytokines, growth factors, chemokines, and adhesion molecules, thus promoting the cellular recruitment and angiogenesis necessary to maintain and amplify local inflammation. IL-1 $\beta$ and TNF- $\alpha$ are therefore strongly involved in the mechanism of erosion and osteocartilaginous destruction. On the other hand, IL-17 produced by activated Th1/Th17 lymphocytes is an essential cytokine in RA. It has feedback on the APCs and activates, throughout the inflammation, the antigenic presentation, in addition, it acts on the endothelial cells, promoting angiogenesis within the inflammatory site. IL-17 plays an important role in osteocartilaginous erosion and destruction, in fact, it activates fibroblast-like synoviocytes, chondrocytes as well as osteoclasts, cell types predominantly involved in osteocartilaginous damage (Figure 1) (X. Li et al., 2010).

Following activation of endothelial cells, increased vascular permeability, and degradation of the basement membrane and extracellular matrix, endothelial cells can then migrate to the inflamed synovium to form a new capillary. VEGF levels are correlated with the severity of the disease, particularly in the early phase (Sone et al., 2001). An increase in the level of VEGF and thus in the vascularization is correlated with the active phases (ie the RA flares) (Paleolog, 2002). On the other hand, IL-1 and TNF- $\alpha$ induce the synthesis of growth factors responsible for the abundant proliferation of fibroblast-like synoviocytes in the synovial membrane. fibroblast-like synoviocytes appear to behave similarly to certain cancer cells with a lack of apoptosis, so this could explain the proliferation of this cell type in the joint (Pap et al., 2000). The invasion of the synovial membrane and sometimes the cartilage of the joint is at the origin of the osteocartilaginous destruction found in RA. Finally, osteoclasts play an essential role in the destruction of the joint. They are activated via the RANK/RANKL signaling pathway stimulated by cytokines produced by Th1 lymphocytes (K. W. Kim et al., 2007) (Figure 1). 

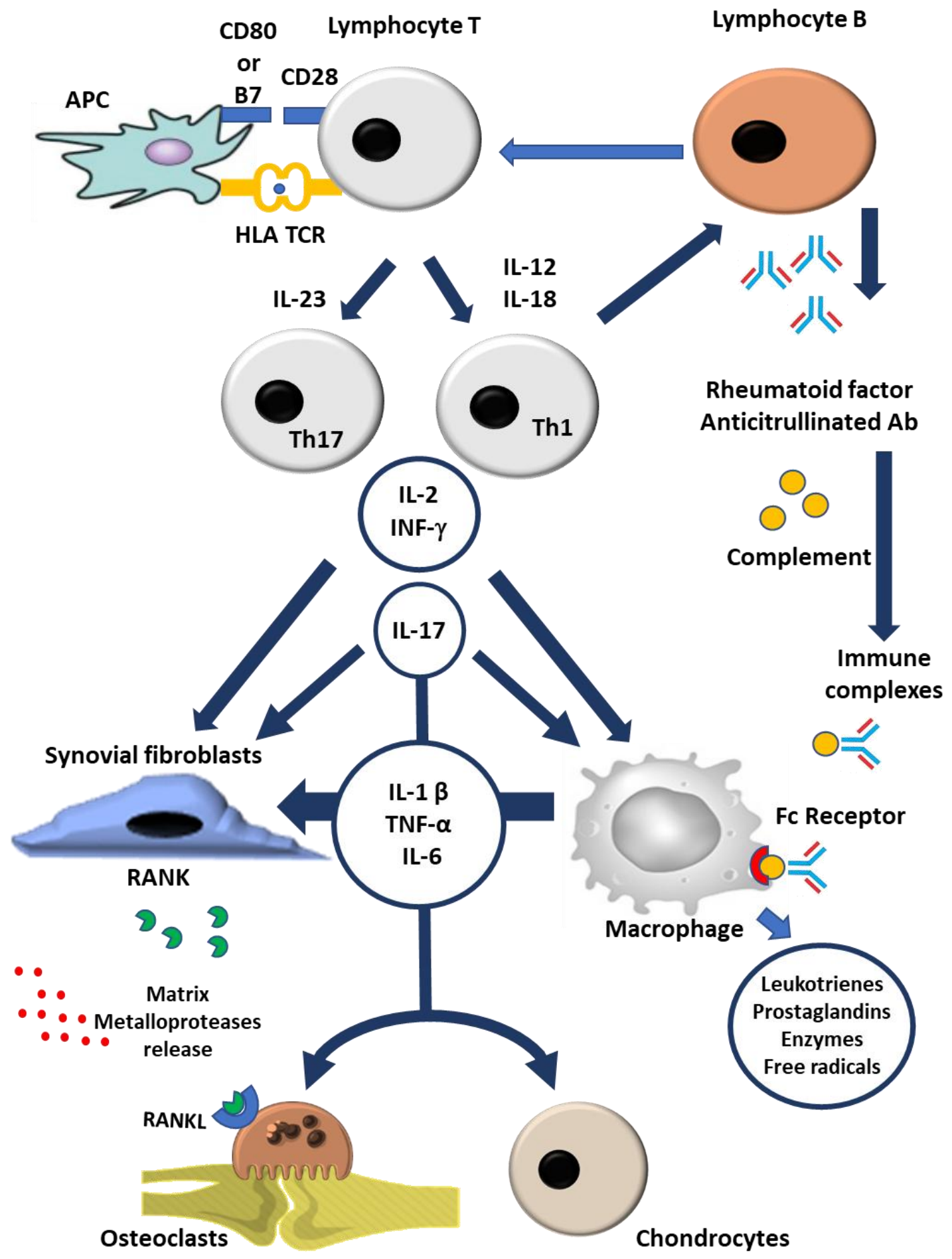

Figure 1: Physiopathology of rheumatoid arthritis 


\section{Therapeutic strategy in the treatment of RA}

Drugs used in the treatment of RA can be divided into two categories. One can distinguish, on the one hand, the crisis treatments used during inflammatory outbreaks of RA to reduce pain and swelling quickly over a short period, and on the other hand, the disease-modifying antirheumatic drugs (DMARDs) put in place as soon as possible following the diagnosis of RA. The latests allow to slow down, even to stop the progression of the disease and to obtain remission which constitutes the primary objective of RA therapy.

\subsection{Arthritis-related pain}

The analgesic treatments conventionally used during inflammatory flares are nonsteroidal anti-inflammatory drugs (NSAIDs) (van Laar et al., 2012). Examples include the "profens" (ibuprofen, ketoprofen, flurbiprofen) or other drugs such as diclofenac, naproxen, piroxicam, niflumic acid, indomethacin, celecoxib. This therapeutic class allows rapid relief of the patient but the drug duration of action is short (van Laar et al., 2012). They have no impact on the progression of the disease from a structural or functional point of view and do not reduce joint erosion (van Laar et al., 2012). Moreover, conventional NSAIDs are associated with gastrointestinal side effects that can result in severe bleeding, perforation, and obstruction (Laine, 2002).

GCs, which are steroidal anti-inflammatory drugs derived from cortisol, are the second pharmacological class used in symptomatic manifestations of RA (Ferreira, Ahmed Mohamed, \& Emery, 2016). They possess a greater anti-inflammatory and immunosuppressive action than NSAIDs. GCs are given orally at low doses. Treatment should be as short as possible and dose reductions should be considered as soon as possible to minimize side effects and withdrawal syndrome (Hochberg, 2004). Chronic misuse of GCs leads to the emergence of strong side effects such as diabetes, high blood pressure or Cushing syndrome (McDonough, Curtis, \& Saag, 2008; Saag et al., 1994). Because of the ubiquitous expression of the GC receptor (Nicolaides, Galata, Kino, Chrousos, \& Charmandari, 2010; Vandevyver, Dejager, \& Libert, 2012), GC local therapeutic activity is diluted by side activity in other organs. Therefore, patients require repeated administrations of high GCs doses to reach a sufficient anti-inflammatory activity in the tissue of interest (Saag, 1997). The GC can also be administered locally by intra-articular injection, which allows obtaining a very important but still transitory efficiency (Af Klint et al., 2005).

\subsection{Disease-modifying antirheumatic drugs}

DMARDs can be divided into three groups, disease-modifying antirheumatic drugs (DMARDs), anti-cytokine biologic drugs and cellular immunotherapy. DMARDs constitute a very heterogeneous pharmacological class allowing a reduction of joint swelling, synovitis, and pain as well as a decrease of the markers of the inflammatory syndrome. They also limit the progression of erosion and improve the functional abilities of the patient.

Methotrexate (MTX) is the first-line therapy for long-term treatment of RA because of its efficacy and moderate cost. It is an antifolic agent that has anti-inflammatory and immunosuppressive action. Because of its mechanism of action, it is necessary to institute folic 
acid supplementation from the beginning of treatment with MTX. Sulfasalazine is cleaved in the body into salicyl derivative and sulfonamide. Sulfasalazine and leflunomide, an immunosuppressive drug, are prescribed in the case of intolerance to MTX. Two other immunosuppressive molecules, ciclosporin A and azathioprine have only a limited place in the therapy of RA. Finally, hydroxychloroquine, a drug aiming to fight against malaria was added to the DMARDs list. It is used as triple therapy in combination with MTX and sulfasalazine following a failure of MTX monotherapy (Hazlewood et al., 2016).

The biological anti-cytokine and cellular immunotherapy treatments are indicated in the second line and in the long-term treatment of RA following the failure of MTX monotherapy and if patients have poor prognostic factors (structural damage or progression, strongly active RA, high inflammatory syndrome, high autoantibody level). (Rein \& Mueller, 2017) All antibodies on the market are targeting either TNF- $\alpha$, IL-1 $\beta$ or IL-6 (Rein \& Mueller, 2017). However continuous systemic administration of biologics may induce side effects and mostly generates opportunistic infections (Downey, 2016; J. A. Singh, 2016). About half of the patients have to interrupt the treatment due to side effects (Buch, Bingham, Bryer, \& Emery, 2007). Moreover, a recent report related $6 \%$ of cases of patients who are refractory to the treatment with the biologics mentioned above with no real explanation at the moment for the reason why these patients do not respond to the treatment (Kearsley-Fleet et al., 2018)

\section{Nucleic acids as new molecules for the treatment of rheumatoid arthritis}

While there are no drugs from nucleic acids marketed as anti-cytokine drugs, there are several attempts of knocking down mRNA or microRNA in the treatment of RA. RNA interference employing siRNA is a widely used approach to achieve the silencing of the gene of interest (Figure 2). It consists of double-stranded RNAs of 21-23 base pairs bind to a multi-protein complex in the cytoplasm, known as RISC for RNA-induced silencing complex. During assembly of RISC, one of the two siRNA strands, referred to as the passenger strand, is released, whereas the other strand (guide strand) binds to the argonaute protein, Ago2 (Meister et al., 2004) (Figure 2). This strand then guides RISC to its complementary target RNA, which is finally cleaved by the RNase activity located in the Ago2 protein, triggering its destruction (Figure 2) (J.-J. Song, Smith, Hannon, \& Joshua-Tor, 2004). The site of action of siRNA is always the cytoplasm. Targets for siRNA in RA are mainly cytokines interleukin-1 (IL-1), interleukin-6 (IL-6) and IL-18 (Khoury et al., 2008), TNF- $\alpha$ (Aldayel et al., 2018; Aouadi et al., 2009; Howard

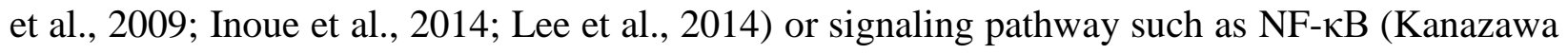
et al., 2016; Wang et al., 2017; Zhou et al., 2014), Notch1 (M. J. Kim et al., 2015; Zhao \& Zhang, 2018), c-Rel (Fan et al., 2018), transforming growth factor $\beta$-activated kinase-1 (TAK1) (Luo et al., 2017), C-C chemokine receptor type 5 (H. Duan, Yang, Fang, Ding, \& Xiao, 2014), STAT1 (Scheinman, Trivedi, Vermillion, \& Kompella, 2011), Polo-like kinase-1 (PLK-1) (Wada et al., 2007). Whether the siRNA was delivered as free or by physical or chemical means, in all cases, an impact on inhibiting the progression of RA in animal models was observed. 


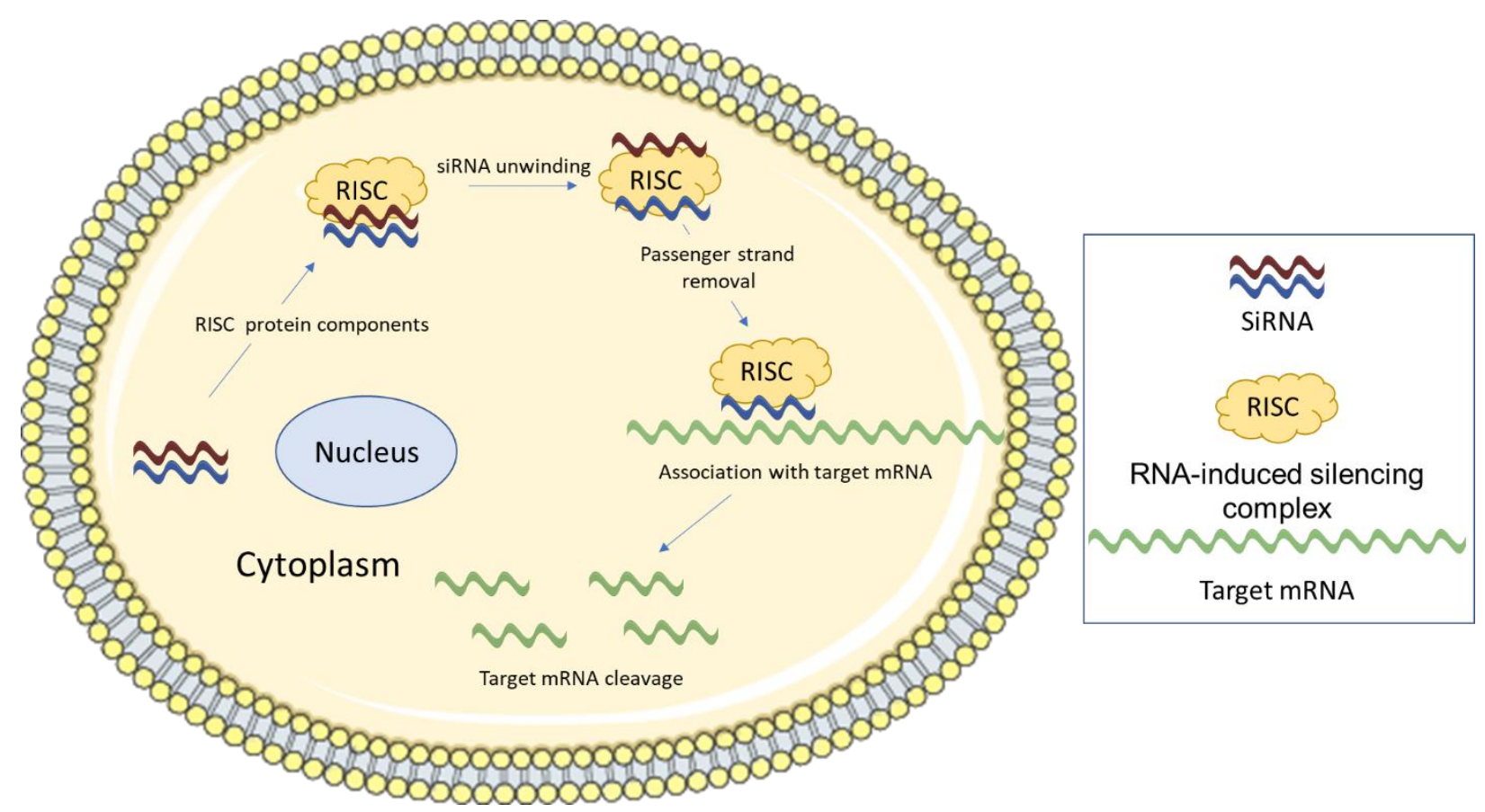

Figure 2: Mechanism of action of siRNA

MicroRNAs (miRNAs) represent a class of small endogenous non-coding RNA molecules that play important roles in the regulation of gene expression impacting cell differentiation, proliferation, and survival (Bartel, 2004). miRNAs typically bind to complementary target mRNAs, resulting in mRNA translational inhibition or degradation. The recently improved understanding of miRNA's biogenesis and mechanisms of action has cast a new light on those molecules. The initial concept of miRNAs as solely developmental regulators has been substantially expanded as miRNAs have been found to be dysregulated in numerous diseases, including cancer, hepatitis, cardiovascular and inflammatory diseases (Chen, Papp, Szodoray, \& Zeher, 2016; Esteller, 2011). Most miRNA sequences are encoded within introns of protein-coding genes with some miRNAs having their own promoter region. The biogenesis of miRNAs begins with the transcription of a long primary-microRNA transcript (pri-miRNA) by an RNA polymerase (Figure 3). The pri-miRNA is then cleaved by the Drosha/DGCR8 protein complex generating a pre-miRNA followed its migration into the cytosol (Figure 3). There, the terminal loop of the pre-miRNA is cleaved by RNase III Dicer and cofactor TAR RNA binding protein. The resulting two miRNAs strands then bind to AGO proteins forming the RISC complex (Figure 3). Within the RISC complex, the two miRNA strands are unwound and one of the strands is selected. The RISC complex containing the selected mature single miRNA strand is then able to bind to mRNAs with complementary nucleotide sequences resulting in translational repression or mRNA degradation (Figure 3) (Stenvang, Petri, Lindow, Obad, \& Kauppinen, 2012). Unlike siRNA that are highly specific, miRNAs can regulate multiple mRNA targets leading to potentially increased efficacy in controlling gene expression. Consequently, new strategies have been developed focusing on miRNA as therapeutic candidates (in the form of 
miRNA mimics) or as molecular targets for the development of new therapeutics (in the form of Anti-miRNA) (Rupaimoole \& Slack, 2017).

Analysis of the miRNA profiles of autoimmune disease patients has revealed numerous disruptions in the expression of particular miRNAs such as miRNA-155, -146a, -326, -21, and -181 (R. Hu \& O'Connell, 2013; Rauniyar, Wu, \& Yang, 2011; R. P. Singh et al., 2013). Overexpression of miRNA-146a and miRNA-155 have been shown to stimulate macrophages' NFkB pathway and the secretion of pro-inflammatory cytokines such as TNF- $\alpha$, IL- $1 \beta$, and IL-17 (Bala et al., 2011; O’Connell, Rao, \& Baltimore, 2012). Interestingly, recent clinical studies have revealed that monocytes in RA patients present a significantly higher expression level of miRNA-155 compared to healthy control, with the miRNA-155 concentration correlating closely with the severity of the inflammation (Blüml et al., 2011; Elmesmari et al., 2016). The critical role of miRNA-155 in RA has been further demonstrated in mice, as subcutaneous injection of collagen in miRNA- 155 gene-deficient animals did not lead to the development of clinical signs of arthritis such as an increase in paw swelling and decrease in grip strength (Blüml et al., 2011). At the cellular level, miRNA-155 has been identified as a key regulator of monocyte/macrophage apoptosis (Rajasekhar et al., 2017) and was shown to be overexpressed in synovial fibroblasts (Stanczyk et al., 2008). miRNA-155 has also been shown to polarize macrophages towards a proinflammatory phenotype (Zhang et al., 2018). From clinical samples, different miRNAs were regulated in patients having RA. Based on a recent observation, miRNA-223 may be a potential marker of disease activity since decreased serum level of miRNA -223 was found after therapy in early RA (Filková et al., 2014). Concentrations of miRNA-16, -132, -146a, -155 and -223 in synovial fluid and plasma were measured in patients with RA (Murata et al., 2010). Results showed that synovial fluid concentrations of miRNA -16, $-132,-146 a$, and -223 were significantly lower than their plasma concentrations, and there was no correlation between plasma and synovial fluid miRNAs. Nevertheless, miRNA-16, -132, $-146 \mathrm{a}$, and -223 were found to be over-expressed in synovial fluid and blood plasma of patients compared to healthy controls (Murata et al., 2010). Finally, the miRNA expression in macrophages from patients with RA was recently determined. Seven miRNAs, namely miRNA-99a, -100, -125b, -199-3p, -199-5p, -152 and -214 were downregulated and only miRNA-223 was upregulated (Ogando et al., 2016).

In cases were miRNAs are down-regulated, an approach is to reequilibrate the level of miRNA by the administration of the relevant lacking sequence. In the case were some miRNA are up-regulated the best strategy to inhibit miRNA's activity is to develop Anti-miRNA oligonucleotides. Anti-miRNAs are natural or chemically-modified (e.g. phosphorothioate, 2'OMe, locked nucleic acid) antisense oligonucleotides (ASO) designed to bind to selected miRNA and induce RNAse-H-mediated cleavage. Unfortunately, similarly to siRNA and other nucleic acid drug candidates, Anti-miRNAs are relatively unstable in vivo and chemical modifications may alter their biological properties. Furthermore, equally to conventional anti-inflammatory drugs, Anti-miRNA may cause severe off-target side effects such as reduced protective immunity, fibrosis, or liver steatosis (Alivernini et al., 2018). Small are the studies that have been carried out in vivo on the inhibition of mi-RNA. One of the most important was 
carried out on the inhibition of miRNA-34a. As miRNA-34a was shown to participate in cell apoptosis, immune activation and bone metabolism, Dang et al. (Dang et al., 2017) investigated the effects of chemically modified anti-miRNA-34a on RA in collagen-induced arthritis (CIA) mice model. Arthritis scores decreased as well as joint swelling was alleviated with the anti-miRNA-34a treatment. The expression of inflammatory cytokines was concomitantly reduced. Anti-miRNA-34a delivery significantly decreased the percentage of $\mathrm{T}$ cells present including Th1, Th2, Th17, and regulatory T cells. Furthermore, anti-miRNA-34a-treated CIA mice demonstrated decreased inflammatory-induced bone loss. (Dang et al., 2017)

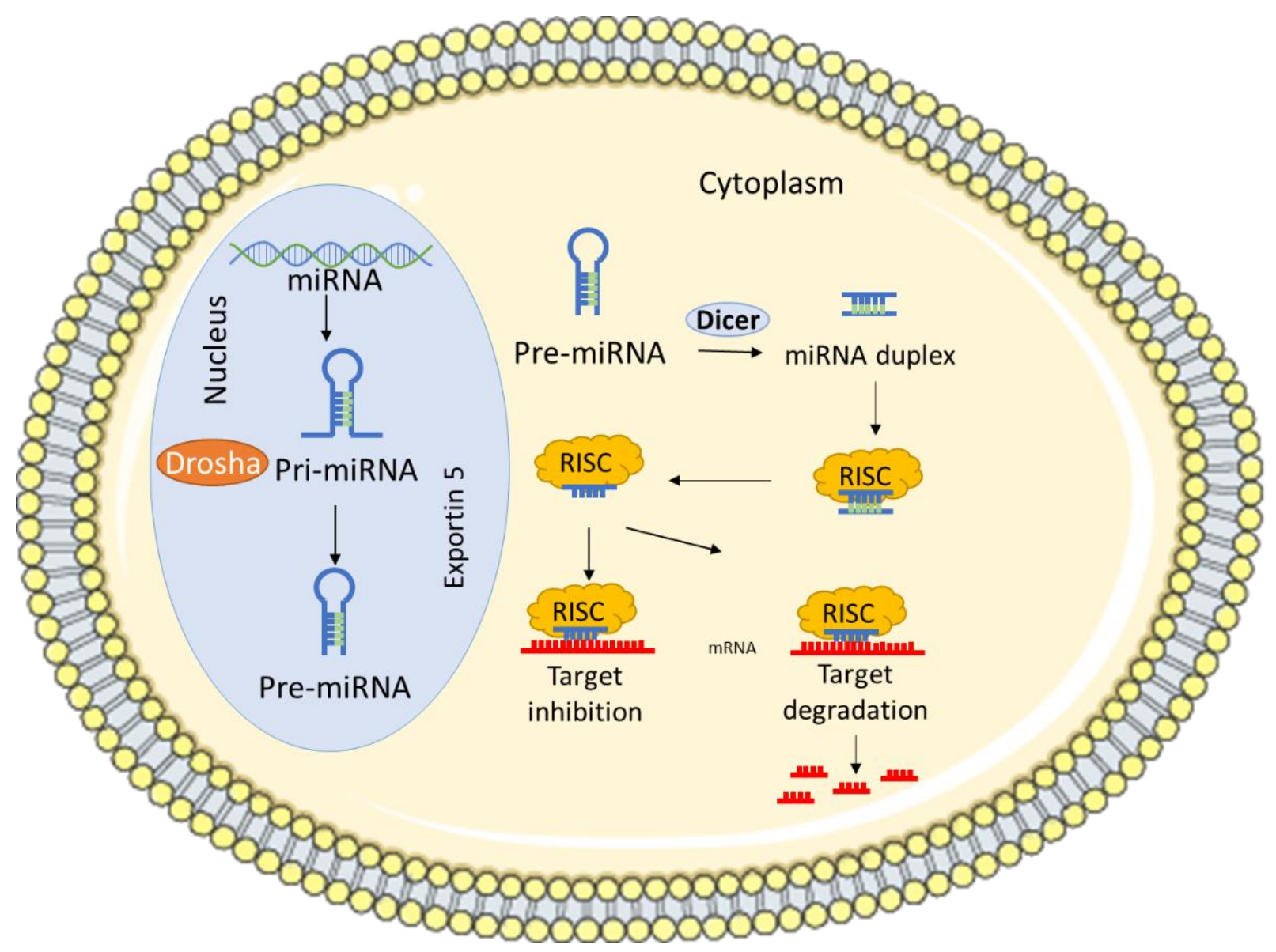

Figure 3: Mechanism of action of miRNA

\section{The rationale for applying nanomedicines to GCs and nucleic acid delivery in RA}

The major drugs that are discussed in this review, GCs and nucleic acids, display several issues when administered under the free form. At first, when treated, patients require repeated administrations of high GCs doses to reach a sufficient anti-inflammatory effect in the tissue of interest inducing in parallel strong side-effects as mentioned earlier (Saag, 1997). At second, nucleic acids anti-miRNA, miRNA or siRNA face several hurdles that slow down the process by which they could reach clinical translation. The first hurdle encountered by nucleic acids is their poor stability in biological fluids (Layzer et al., 2004; Whitehead, Langer, \& Anderson, 2009). 
The half-life of free siRNA in a biological fluid is very short, and it is easily degraded by nuclease (Behlke, 2008). Moreover, it is noteworthy that because of their high molecular weight their hydrophilicity and the presence of negatively charged phosphate groups, they poorly cross cell membranes and have difficulties to reach the cytoplasm where they could exert their therapeutic activity (Whitehead et al., 2009). In addition, the application of siRNA in therapy is also limited by the immunogenicity and non-target effect of some siRNA molecules (Jackson et al., 2003; Jackson \& Linsley, 2010; Whitehead et al., 2009).

Nanotechnologies are taking advantage of the specific physiopathology of inflamed tissues and of a vascular enhanced permeability effect to address encapsulated molecules to the tissue of interest by passive diffusion in the diseased area (Dolati et al., 2016; Pham, 2011). Accumulation of therapeutic nanoparticles in inflamed joints could improve anti-inflammatory activity while avoiding the administration of high doses and thus reducing side effects (Lorscheider, Tsapis, Simón-Vázquez, et al., 2019; Lorscheider, Tsapis, ur-Rehman, et al., 2019; Ozbakir et al., 2014). Regarding nucleic acids, it was shown that drug delivery using nanomedicines (Apparailly \& Jorgensen, 2013) for targeted delivery or micromedicines for local controlled delivery (De Rosa et al., 2002) could solve much of the issues related to their administration. In this review, we will approach the different types of nanomedicines used for the delivery of GCs and nucleic acids.

\section{Nanomedicines for glucocorticoids}

To overcome the obstacles described above in the application of GCs in the treatment of RA, many nanomedicines have been developed (Feng \& Chen, 2018; Gauthier et al., 2018; Knudsen et al., 2015; Krakovičová, Etrych, \& Ulbrich, 2009; Silva, Lopes, Lobo, \& Amaral, 2015; Qin Wang et al., 2016). They are all aiming to efficiently load GCs, target specific tissues or cell types, and control drug release for a long period of time (Lühder \& Reichardt, 2017; Q Wang \& Sun, 2017) as summarized in Table I.

\subsection{Liposomes}

Liposomes are vesicular vectors composed of one or several lipid bilayers surrounding an aqueous core (Figure 4). Liposomes have been widely used for GCs delivery (Ozbakir et al., 2014). Conventional liposomes are opsonized by plasma proteins resulting in rapid clearance by the monocyte phagocytic system (MPS) when administered intravenously (Owens \& Peppas, 2006; G. Song, Petschauer, Madden, \& Zamboni, 2014). A strategy to design stealth ${ }^{\circledR}$ liposomes has been developed consisting in modifying vesicle surface with polyethylene glycol (PEG) chains to avoid immediate phagocytosis and to enhance circulation time in the blood (Allen, Hansen, Martin, Redemann, \& Yau-Young, 1991; Klibanov, Maruyama, Torchilin, \& Huang, 1990). GCs can be encapsulated either in the aqueous compartment of liposomes in the form of salts (U Rauchhaus et al., 2009) or within the bilayer in their hydrophobic form (Hong Kee, Hack Joo, Hyun Pyo, Lee, \& Si Myung, 1988) (Figure 4).

Conventional liposomes (Table 1) made of 1,2-dipalmitoyl-sn-glycero-3-phosphocholine (DPPC) were first applied to the encapsulation of prednisolone palmitate, a lipidic prodrug of prednisolone, and showed higher anti-inflammatory activity than prednisolone hemisuccinate, 
following intravenous injection into rats, using a $\lambda$-carrageenin paw edema test (Hong Kee et al., 1988). Other formulations were designed with dexamethasone. Liposomes composed of DPPC, 1,2-dipalmitoyl-sn-glycero-3-(phosphor-rac-(1-glycerol)), sodium salt (DPPG), and cholesterol (50:10:40 mol\%) were also given intravenously in an experimental arthritis model in mice and rats (Anderson et al., 2010; Rauchhaus, Schwaiger, \& Panzner, 2009). In both cases, the PEG-free formulations considerably reduced the dose and/or frequency required to treat RA, with the potential to enhance or prolong therapeutic efficacy and limit side-effects (Anderson et al., 2010; Rauchhaus et al., 2009a; Rauchhaus et al., 2009b).

Liposomes coated with PEG (named PEGylated or stealth®) (Table 1) were designed to deliver prednisolone in an adjuvant-induced arthritis (AIA) model in rats (Metselaar, Wauben, Wagenaar-Hilbers, Boerman, \& Storm, 2003). A single injection of $10 \mathrm{mg} / \mathrm{kg}$ resulted in the complete remission of the inflammatory response for almost a week. In contrast, the same dose of unencapsulated prednisolone did not reduce inflammation, and only a slight effect was observed after repeated daily injections (Metselaar et al., 2003). It was further shown that this liposomal formulation protects against cartilage matrix destruction during experimental arthritis by inhibiting protease expression and activity in the inflamed synovium (Hofkens, Storm, Van den Berg, \& Van Lent, 2011). Avnir et al. (Avnir et al., 2008) also designed PEGylated liposome formulation for high entrapment of methylprednisolone hemisuccinate which exhibits optimal pharmacokinetic profiles of long-circulating nanomedicines in both rats and beagle dogs. The superior therapeutic efficacy of the liposomal formulation over that of the free drug was shown in arthritic rats, both in early and in peak disease stages (Avnir et al., 2008). Besides, the therapeutic activity and adverse effects induced by 3 different GCs encapsulated in long-circulating liposomes were compared in arthritis induced in mice in an attempt to further optimize the therapeutic index of liposomal GCs (Van den Hoven et al., 2011). The GCs (dexamethasone, budesonide) of higher potency than prednisolone exhibited an increased efficacy over the non-encapsulated ones. However, side effects such as reduction of body weight and hyperglycemia were observed due to the amount of sustained free GC released after intravenous liposome administration (Van den Hoven et al., 2011). As the drug release rate is dependent on liposome composition, the nature of the drug and the method of encapsulation, Hosseini et al (Hosseini, Maleki, Eshraghi, \& Hamidi, 2016) introduced a liposome formulation composed of phosphatidylcholine that could significantly reduce the release rate of GCs. Prednisolone release profiles from liposomes displayed near-zero order kinetics with a very low initial burst. In in vivo experiments in rats, no initial plasma concentration burst was observed. The slow release of GC led to a stable GC concentration in the blood circulation for a longer time (about 2.5 times) when compared with the control group (Hosseini et al., 2016). However, no comparison with other liposomal formulation was carried out.

Active targeting was also approached for the delivery of GCs in RA (Table 1). Several ligands were attached to the liposomal surface for this purpose. One of the first studies consisted of attaching RGD peptides to long-circulating PEGylated liposomes containing dexamethasone phosphate targeting $\alpha v \beta 3$ integrins overexpressed on angiogenic vascular endothelial cells at sites of inflammation. One single intravenous injection of these targeted liposomes resulted in a 
strong and long- lasting antiarthritic effect in adjuvant-induced arthritis in rat (Koning et al., 2006). Because activated macrophages are known to greatly overexpress the folate receptor, folate-liposomes were shown to selectively accumulate in arthritic rat paws to a greater extent than non-targeted liposomes (Poh et al., 2017) (Poh, Chelvam, Ayala-Lopez, Putt, \& Low, 2018). When the folate liposomes containing betamethasone were administered to arthritic rats, animals exhibited less paw swelling, lower arthritis scores, a reduction in bone erosion, less splenomegaly and better maintenance of body weight when compared with untreated or non-targeted liposomes containing betamethasones (Poh et al., 2017). It has been recently reported that dexamethasone palmitate-loaded liposomes decorated with a sialic acid conjugate provide a reinforced accumulation in peripheral blood neutrophils, a better accumulation in the joints and a stronger anti-inflammatory effect in an RA model induced in Rats. (Hu et al., 2019). Finally, delivery of p-coumaric acid encapsulated into mannosylated liposomes was shown to target specifically synovial macrophages and inhibited osteoclast formation and bone resorption in an RA mice model (Neog \& Rasool, 2018). Among all these formulations, only a few have reached the clinical stage. In the field of inflammatory diseases, the company Enceladus ${ }^{\circledR}$ is launching a phase $2 \mathrm{~b}$ clinical trial with a liposomal prednisolone formulation.

\subsection{Polymeric Micelles}

Polymeric micelles are colloidal, supramolecular nanomedicines, with a diameter ranging from 10 to $100 \mathrm{~nm}$, usually formed from the self-aggregation in an aqueous medium of amphiphilic block polymers. (Jhaveri \& Torchilin, 2014). The micellar structure of amphiphilic monomers is entropically favored and occurs above their critical aggregation concentration to results in the formation of a core-shell structure, where the hydrophobic part of the polymer is located inside (core) and the hydrophilic is on the outside (shell) (Lu, Zhang, Yang, \& Cao, 2018). Encapsulated hydrophobic or low water-soluble drugs such as GCs are usually located in the hydrophobic inner core (Figure 4) and can be released by diffusion (Amjad, Kesharwani, Amin, \& Iyer, 2017). The hydrophilic shell and the small size provide some protection in limiting opsonin adsorption and good stability in biological fluids which contribute towards a longer blood circulation time. Currently, there are reports that amphiphilic compounds can be simply divided into two different systems: the first one consists of block copolymers. Typically, PEG is used as a hydrophilic block, while the hydrophobic block can be composed of poly ( $\varepsilon$-caprolactone) (Khodaverdi et al., 2019; Q Wang et al., 2016) poly-L-cysteine (H. C. Kim et al., 2017). These systems formed by amphiphilic compounds present the advantages of being simple to obtain through simple chemical reactions but lack the potential for wide optimization and chemical modification. The second systems are the amphiphilic dendrimers or dendrons, which on the contrary can be synthesized by customization. Amphiphilic dendrimers have the ability of amphiphilic compounds to form micelles and display many additional advantages such as regular molecular structure, accurately controlled spatial structure and abundant surface groups (X Liu et al., 2014).

Up to now, the potential of micelles as carriers for rheumatoid arthritis treatment has not been extensively explored. Only a limited number of amphiphilic molecules forming micelles have 
been developed and reported, such as poly(ethylene glycol)-poly ( $\varepsilon$-caprolactone) (PCL-PEG), polysialic acid-polycaprolactone (PSA-PCL) (Koo, Rubinstein, \& Önyüksel, 2011; Wang et al., 2016, 2019; Wilson, Zhang, Silvers, Forstner, \& Bader, 2014). The work by Wang et al. (Qin Wang et al., 2019) on PCL-PEG demonstrated that it was possible to deliver low-dose of dexamethasone to inflamed joints. These stable micelles, with a diameter lower than $100 \mathrm{~nm}$ and a high encapsulation efficiency, demonstrated a relatively long persistence of dexamethasone in plasma compared with the free drug. It led to a better anti-inflammatory efficacy than free dexamethasone in the treatment of arthritis in rats (Wang et al., 2019).

In a head-to-head comparison study, with four established nanomedicines formulations of dexamethasone, Quan, and co-workers (Quan et al., 2013) compared the anti-inflammatory effects of micelles and liposomes respectively encapsulating the same dose of dexamethasone. It was found in vivo that after a single intravenous injection, the formulations containing dexamethasone in polymeric micelles showed a sustained drug release and prolonged systemic activity, inducing a longer duration of therapeutic activity resulting in better joint protection. Although liposomes show a very slow release rate in vitro, when used on an AIA rat model, they interact with macrophage-like synovial cells, resulting in rapid release of the encapsulated drugs after lysosomal degradation. Therefore, the duration of its anti-inflammatory effect is much shorter than expected. This indicates that it may be more advantageous to encapsulate GCs with water-soluble micelles than liposomes in the treatment of rheumatoid arthritis.

\subsection{Polymer and lipid nanoparticles}

Several attempts of encapsulating GCs in poly(lactide-co-glycolide) (PLGA) polymer nanoparticles (Figure 4) were achieved with some moderate success due to poor drug loading, drug crystallization, and drug burst release effect (Gómez-Gaete, Fattal, Silva, Besnard, \& Tsapis, 2008; Gómez-Gaete, Tsapis, Besnard, Bochot, \& Fattal, 2007). The most successful results were obtained with betamethasone (Higaki, Ishihara, Izumo, Takatsu, \& Mizushima, 2005; Ishihara, Kubota, Choi, \& Higaki, 2009). In one first study, betamethasone sodium phosphate (BSP) encapsulated in PLGA nanoparticles with a size of 100-200 nm were obtained. They were intravenously administered to AIA in rats and mice with anti-type II collagen antibody-induced arthritis. (Higaki et al., 2005). In both models, the treatment was effective. A single intravenous dose of hydrophilic BSP encapsulated in PLGA nanoparticles could lead to a rapid, complete, and durable resolution of joint inflammation owing to the enhanced and preferential localization of BSP in the inflamed joints. The same dose of free BSP after three administrations only moderately reduced the severity of inflammation. In addition, a histological examination, 7 days after the treatment, showed a significant decrease in the inflammatory cells in the joints (Higaki et al., 2005). The same group also developed several formulations of PEGylated PLGA nanoparticles with a size rangin from 45 to $115 \mathrm{~nm}$, this latest exhibiting the highest anti-inflammatory effect (Ishihara et al., 2009). The authors stipulate that this may have been due to prolonged blood circulation and targeting to the inflamed joint in addition to its sustained release in situ (Ishihara et al., 2009). A recent system was developed in our group inspired by long-circulating liposomes with new features such as a high drug loading and low burst effect as 
compared to PLGA nanoparticles (Lorscheider, Tsapis, Simón-Vázquez, et al., 2019; Lorscheider, Tsapis, ur-Rehman, et al., 2019). It consisted of nanoparticles made of solely a prodrug of GC, dexamethasone palmitate, and PEGylated phospholipids with a drug loading up to about $50 \%$ by weight (Lorscheider, Tsapis, Simón-Vázquez, et al., 2019). The particles were shown to modify the pharmacokinetics of the drug and, in a murine model of arthritis, demonstrated a preferential distribution in inflamed joints (Lorscheider, Tsapis, Simón-Vázquez, et al., 2019; Lorscheider, Tsapis, ur-Rehman, et al., 2019) enhancing the anti-inflammatory effect of dexamethasone compared to the free drug with even inflammation remission observed in animals (Lorscheider, Tsapis, ur-Rehman, et al., 2019).

\subsection{Polymer-drug conjugates}

Besides being entrapped, GCs which are mainly poorly water-soluble drugs can directly be chemically conjugated to water-soluble polymers producing polymer-drug conjugates (PDCs) (Canal, Sanchis, \& Vicent, 2011; Kopeček, 2013) (Figure 4). Currently, polymers such as PEG (X.-M. Liu et al., 2010) or N-(2-hydroxypropyl) methacrylamide(HPMA) (D. Wang et al., 2007) have been successfully used for drug conjugation. In addition, several PDCs based on PEG have been approved for clinical use (Alconcel, Baas, \& Maynard, 2011). In one study involving HPMA-dexamethasone conjugates, the molecular weight was found to be the predominant factor impacting PDC pharmacokinetics (Wei et al., 2017). The increased molecular weight of HPMA-dexamethasone conjugates reduced elimination, leading to lower clearance, longer half-life, and higher systemic exposure (Wei et al., 2017). In the CIA mouse model, Quan et al. demonstrated a much better distribution of the HPMA conjugates (Quan et al., 2016). However, while the inflammation responded more rapidly to dexamethasone HPMA conjugates compared to free dexamethasone, the final clinical score was equal in both cases 30 days after inducing arthritis. Alternative strategies for drug controlled release are based on the inflamed microenvironment using stimuli sensitive bonds that are redox-responsive, temperature-responsive or flare-responsive (Joshi et al., 2018). A very elegant study by Joshi et al. described the development of a hydrogel platform that exhibits disassembly and drug release controlled by the concentration of enzymes expressed during arthritis flares applied to triamcinolone (Joshi et al., 2018). After local injection, a single dose of triamcinolone-loaded hydrogel but not the equivalent dose of locally injected free triamcinolone reduces arthritis activity in the injected paw (Joshi et al., 2018). Although interesting, this system is very different from the others due to the route of administration and to non particulate form but can open perspectives for the design of systemic delivery systems. 


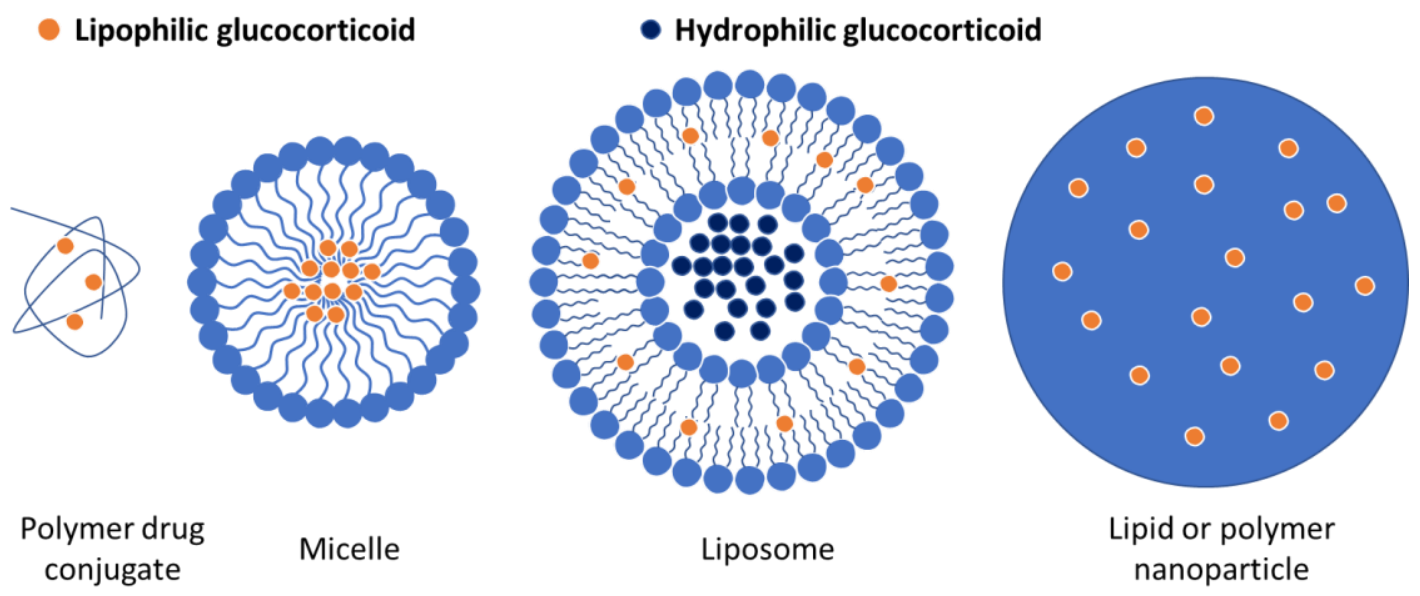

Figure 4: Types of nanomedicines used for the delivery of Glucocorticoids

\section{$7 \quad$ Nanomedicines for nucleic acid delivery in rheumatoid arthritis}

\subsection{Small interfering RNA (siRNAs)}

As discussed above, siRNAs have a potent ability to inhibit the translation of specific genes and are being studied in-depth as a promising alternative to antibodies and small molecules inhibitors (Apparailly \& Jorgensen, 2013; Shuey, McCallus, \& Giordano, 2002). Up to now, siRNA-nanomedicines therapy has accessed the clinics with Patisiran ${ }^{\circledR}$ a siRNA for the treatment of hereditary amyloidosis related to transthyretin produced by the liver that undergoes misfolding and aggregation generating deposits in different tissues (Yasuda et al., 2014). Liver targeting results from its physiological function toward colloidal particles where Kuppfer cells and hepatocytes are natural hosts for nanomedicines (Haussecker, 2014; Yin et al., 2014). There are still many challenges to overcome in targeting other tissues than the liver after systemic delivery of siRNA (Haussecker, 2014). Considering the great potential of siRNA to knock-down cytokine expression, it is important to develop efficient siRNA delivery methods that target tissues such as inflamed joints in RA. Nanomedicines can still provide interesting possibilities for the delivery of siRNAs and there are currently various carriers explored for siRNA delivery in adjuvant-induced arthritis, including cationic liposomes, cationic polymer nanoparticles, cationic dendrimers (Figure 5), that will be discussed in the next sections.

\subsubsection{Liposomes}

As they are quite versatile, liposomes were also tailored to deliver siRNAs. The basic structure consisted of cationic liposomes that can bind siRNA through electrostatic interactions and this complexation can effectively protect siRNA from the degradation by nucleases, induce high cellular internalization, improve the pharmacokinetics compared with free siRNA, and lower renal clearance of siRNA (Leng, Woodle, Lu, \& Mixson, 2009). Some cationic lipids have been frequently used for siRNA delivery, such as 1,2-dioleoyl-3-trimethylammonium-propane (DOTAP)

(Sørensen,

Leirdal,

$\&$

Sioud,

2003), 
N-(1-[2,3-dioleoyl]-propyl)-N,N,N-trimethylammonium chloride (DOTMA) (Ren, Song, Zhang, \& Liu, 2000) and Lipofectamine ${ }^{\circledR} 2000$ from Invitrogen ${ }^{\circledR}$ (S. Zhang, Zhao, Jiang, Wang, \& Ma, 2007). Others are homemade cationic lipids RPR209120 (2-[3-\{bis-(3-aminopropyl)-amino $\}$-propylamino]- $N$-ditetradecylcarbamoylmethylacetamide) (Byk et al., 1998) producing liposomes in the presence of a helper lipid that is dioleoylphosphatidylethanolamine (DOPE). Complexes made between these cationic liposomes and a siRNA silencing TNF- $\alpha$ were obtained by Khoury et al. and systemically delivered in a CIA murine model (Khoury et al., 2008). After weekly injections, systemic and local joint secretion of TNF- $\alpha$ was significantly inhibited, as well as IL-6 and MCP-1 (Khoury et al., 2008, 2006). However, these complexes usually have high charge density on their surface, which can induce non-specific interaction with serum protein leading to aggregation and further adverse effects (Arima, Aramaki, \& Tsuchiya, 1997). To achieve better systemic delivery of siRNA, many authors have considered the use of neutral or even PEGylated lipids to cover liposome surface and reduce protein interactions. However, since the surface is not positively charged, neutral and negative liposomes usually require polymer-mediated encapsulation of siRNA in liposome aqueous core. Compared with surface loading, the core-encapsulation of siRNA allows higher loading efficiency and better stability (S.-D. Li, Chono, \& Huang, 2008). The introduction in the core of auxiliary cationic polymers, such as protamine, can achieve this goal. Protamine can preconcentrate siRNA into the core of liposome through electrostatic binding without significantly increasing liposome size (Alshaer et al., 2018; Peer, Zhu, Carman, Lieberman, \& Shimaoka, 2007). In addition, protamine favors nucleic acid release from the endosome (Amos $\&$ Kearns, 1963) and improves the cytoplasmic release of siRNA. Core encapsulation of siRNA with protamine allowed to successfully deliver siRNA in cancer models (Alshaer et al., 2018; S.-D. Li, Chen, Hackett, \& Huang, 2008; S.-D. Li, Chono, et al., 2008). In RA, Wang et al. (X. Wang, Wang, Sun, \& Fu, 2018) developed a cell-permeable peptide-conjugated liposome-polycation-siRNA complex loaded with a siRNA targeting the ribonucleotide reductase M2 (RRM2), to increase the levels of apoptosis and inhibit the proliferation of fibroblast-like synoviocytes in RA (RA-FLS). These liposomes have a relatively small particle diameter (about $130 \mathrm{~nm}$ ), high siRNA encapsulation efficiency $(>90 \%)$ and high stability. It was confirmed that they can significantly inhibit the expression of RRM2 gene and protein by about $80 \%$ in vivo. It is worth noting that liposomes effectively target RA-FLS, resulting in significantly reduced proliferation and increased apoptosis level of RA-FLS (X. Wang et al., 2018). In addition to cationic, neutral and negative liposomes, another widely studied liposome form is the stable nucleic acid-lipid particle (SNALP) (Figure 5). SNALPs are constructed from a bilayer composed of a mixture of low cationic lipid content and fusogenic lipids to enable cellular uptake and endosomal release of the siRNA cargo. The surface of SNALPs is coated with PEG lipid conjugate, which provides a long circulation time (Morrissey et al., 2005). In a recent study related to SNALP delivery of anti-TNF- $\alpha$ siRNA, it was shown that two doses administered locally by intra-articular injection can efficiently suppress inflammation in an experimental arthritis model at relatively low anti-TNF- $\alpha$ siRNA dose $(1 \mu \mathrm{g})$. Furthermore, treatment with SNALPs leads to a reduced Th1 response (Jansen et al., 2019). 


\subsubsection{Polymer and lipids nanoparticles}

Polymeric nanoparticles have been frequently used as siRNA delivery systems (Shende, Ture, Gaud, \& Trotta, 2019). The most prominent feature of nanoparticle carriers is related to their physical and chemical properties, such as composition, size, shape and surface chemistry which can be precisely tuned (Xu \& Wang, 2015). Polymer carriers can also significantly improve the pharmacokinetics and biological distribution of siRNA (Oh \& Park, 2009). In addition, the number of available surface groups provides the potentialities of chemical modification in order to design targeted delivery and controlled release (Sarett, Nelson, \& Duvall, 2015; Zhang et al., 2018). Polymers commonly used in nucleic acid delivery can generally be divided into natural and synthetic polymers (Oh \& Park, 2009). Natural polymers such as chitosan, cyclodextrin, adenylate, protamine, collagen and cationic polypeptides have been favored due to their good biocompatibility and biodegradability (Howard, 2009; Nimesh, Gupta, \& Chandra, 2011; Posadas, Guerra, \& Ceña, 2010). Chitosan, that can be obtained from exoskeletons of crustaceans, became the most commonly used natural polymer to form nanoparticles with siRNA. This polymer is cheap and easily available. It can also enhance the transport of polar drugs (S. Zhang et al., 2007). Shi et al. synthesized a folate-PEG-Chitosan-diethylethylamine conjugate loaded siRNA (C. Yang, Gao, \& Kjems, 2014). These nanoparticles, not only significantly reduced TNF- $\alpha$ concentration but also significantly improved articular cartilage destruction and bone loss in the Collagen Induced Arthritis model (Shi et al., 2018). Finally, Wang et al. developed a DNA nanodrugs via the conjugation of NF- $\kappa B$ decoy oligodeoxynucleotides) and VCAM-1 targeted peptides onto self-assembled DNA tetrahedrons (Z. Wang et al., 2020). The DNA nanodrugs reduced the level of inflammatory proteins in cells and in a model of AIA in mice. Reduced clinical arthritis index and improved joint rehabilitation were also achieved through efficient delivery of NF-אB decoy oligodeoxynucleotides (Z. Wang et al., 2020).

Synthetic cationic polymers like polyethyleneimine (PEI), polylysine (PLL), and dendrimers (discussed separately below) are commonly used to deliver nucleic acids (Howard, 2009; Nimesh et al., 2011; Posadas et al., 2010; Wu, Chien, Liu, Yan, \& Lin, 2012). Among these polymers, PEI is the most commonly used due to a wide range of molecular weights and many protonated amino groups, resulting in high cationic charge density under physiological $\mathrm{pH}$ values, which provides the ability to bind with nucleic acid through electrostatic adsorption (Oh \& Park, 2009). However, its high surface charge density is responsible for severe toxicity particularly due to strong interactions with negatively charged plasma membrane (Boeckle et al., 2004; Hunter, 2006). In-depth studies show that the toxicity of PEI tends to increase with high molecular weight (Thomas \& Klibanov, 2002) and with the increase of branching (Fischer et al., 2002). The cytotoxicity of PEI can be effectively reduced by removing terminal groups that are not complexed with nucleic acid (Boeckle et al., 2004). Song et al. cross-linked low molecular weight PEI $(\mathrm{Mw}=1.8 \mathrm{kDa})$ through a degradable linker. This carrier that was used to deliver TNF- $\alpha$ shRNA (Interfering RNA with hair-pin configuration), has good biocompatibility, and relatively high transfection efficiency, being very effective in reducing the severity of arthritis in the CIA model (J. Song et al., 2016). Another strategy to reduce PEI toxicity consisted of 
associating PEG to low molecular weight PEI (Mao et al., 2006). Indeed, the presence of PEG can significantly reduce the cytotoxicity of cationic polymers by forming a shielding layer, which can protect the polymer structure from damage and degradation in the body environment. It is worth noting that both the chain length and the grafting density of PEG have a great influence on siRNA condensation and stability (Oh \& Park, 2009). Indeed, complexation of siRNA with a series of PEG derivatives of PEI demonstrated that high PEG chain density and a size of 0.55 kilodaltons cannot fully protect siRNA from nuclease. In contrast, other derivatives with PEG chain molecular weight greater than 2 kilodaltons protect siRNA from ribonuclease degradation.

Rare are the papers that developed solid lipid nanoparticles for siRNA delivery in RA. Aldayel et al. (Aldayel et al., 2018) complexed TNF- $\alpha$ siRNA with biocompatible cationic lipids, and then incorporated the nanocomposite into an acid-sensitive polyethylene glycol (2000)-hydrazone-stearic acid (C18) derivative producing in final lipid nanoparticles (Aldayel et al., 2018). Their use in a mouse model of collagen antibody-induced arthritis demonstrated a reduction of paw thickness, bone loss, and improvement of the histopathological scores (Aldayel et al., 2018). The authors further evidenced that surface modification of the acid-sensitive sheddable PEGylated nanoparticles with mannose, a ligand to mannose receptors present in chronic inflammation sites significantly increases the targeted delivery of the nanoparticles to these areas (O'Mary et al., 2017).

\subsubsection{Dendrimers}

Cationic dendrimers have also attracted the attention of researchers as carriers for nucleic acid (Biswas \& Torchilin, 2013; Dzmitruk et al., 2018; Ferenc et al., 2013). In an equal way to other cationic polymers, they have the ability to protect nucleic acid from nuclease degradation and improve their biopharmaceutical properties (Abbasi et al., 2014; Bauer \& Amis, 2001; Caminade, Ouali, Laurent, Turrin, \& Majoral, 2015; Mintzer \& Grinstaff, 2011). The second difference with other cationic polymers is related to the synthesis leading to precise and controllable spatial structure and molecular weight, especially the number and structure of terminal groups on their surfaces. It provides rich possibilities for nucleic acid binding (Deriu et al., 2018). A large number of functional terminal groups are another advantage of dendrimers, which not only can bind a large number of nucleic acids on their periphery, but also provides a large space for customized functionnalisation. In the field of RA treatment, a dendrimer with 12 azadiphosphonate groups on a phosphorus-based scaffold, has shown good anti-inflammatory effect by themselves without any drug loading (Hayder et al., 2011). In addition, studies have shown that dendrimers can also perform well in prolonging the circulating time in vivo (Maeda, 2010). These advantages make their application in nucleic acid delivery very appealing (Bohr et al., 2017; Motoyama et al., 2015; Perise-Barrios et al., 2014). However, there are not many studies using dendriplexes in the field of RA. Jensen et al. were the first to show that polyamidoamine dendrimers associated with anti-TNF- $\alpha$ siRNA were able to significantly induce gene-silencing (Jensen et al., 2012). This observation was further confirmed by Pandi et al. with the same anti-TNF- $\alpha$ siRNA (Pandi et al., 2018). The reason why there are not many experiments 
using polyamidoamine dendrimers by systemic delivery with siRNA might be due to their toxicity and strong affinity to the MPS. It could be worth exploring amphiphilic dendrimers which can form a micellar structure in aqueous solution by self-assembly. At present, amphiphilic dendrimers have emerged in siRNA delivery carriers with impressive effects mainly in anti-tumor applications (Liu et al., 2014; Liu et al., 2015; Yu et al., 2012).

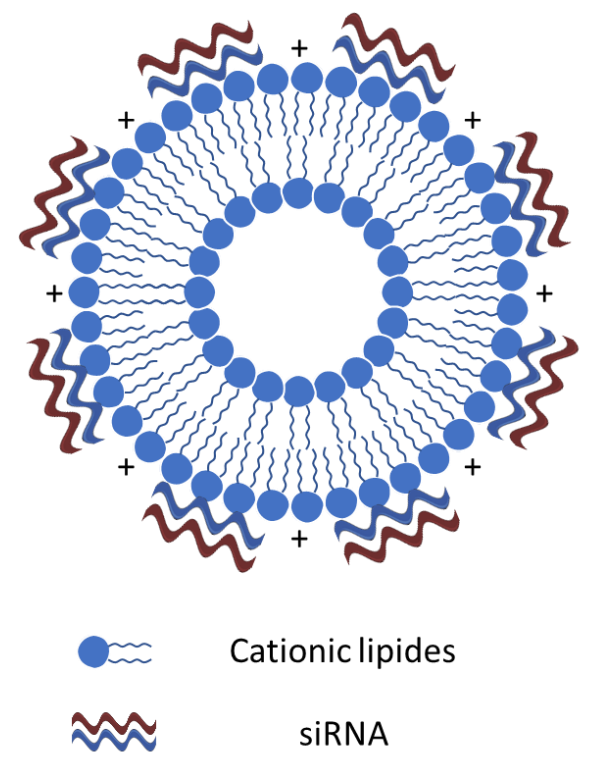

Cationic liposomes

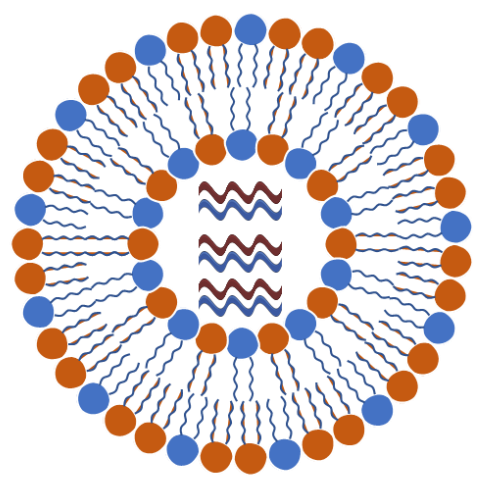

Fusogenic lipides

Cationic lipides

$\approx$ siRNA

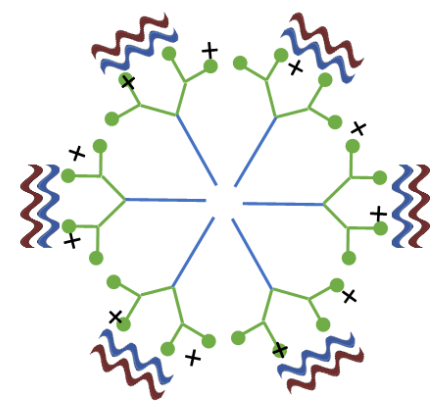

$\approx$ SiRNA

SNALP

Amphiphilic dendrimer

Figure 5 :

\subsection{Combined nucleic acid-drug delivery}

Due to the complex physiopathology of RA that involves a variety of related cells and cytokines (Alghasham \& Rasheed, 2014; Burmester, Feist, \& Dörner, 2014; Siebert, Tsoukas, Robertson, \& McInnes, 2015), it is difficult to achieve an ideal therapeutic effect with one single small molecule drug or one anti-cytokine therapy due to the large number of targets that one of these drugs should reach. It appears more effective to combine two therapeutic approaches with different mechanisms of action. When multiple therapeutic agents target the same cellular pathway, they can cooperate to obtain a higher therapeutic effect and higher targeting selectivity (Saraswathy \& Gong, 2014). Based on these considerations, developing a new delivery platform to deliver GCs and siRNA together appears a simple, direct and feasible method. Compared with single delivery, the simultaneous delivery of two loaded drugs by one carrier can reduce the loss in the delivery process, improve the delivery efficiency, and decrease side-effects. In the co-delivery strategy for RA, the primary problem to be solved is to load both hydrophobic glucocorticoid and hydrophilic siRNA in the same carrier. A carrier platform with co-delivery capability usually needs to share a positively charged surface in order to bind nucleic acid by electrostatic adsorption and the ability to encapsulate hydrophobic small molecule drugs. Wang 
et al. successfully constructed a polymeric hybrid micelle system with two similar amphiphilic copolymers polycaprolactone-polyethyleneimine (PCL-PEI) and polycaprolactone-PEG (PCL-PEG). The polymeric mixed micelle system can deliver dexamethasone and anti- NF-KB siRNA together. Although dexamethasone and siRNA are loaded at the same time, the particle diameter of the polymeric mixed micelle diameter is still controlled within a small range (around $100 \mathrm{~nm}$ ), and the surface is slightly positively charged as demonstrated by zeta potential measurements. The mixed micelle system has also a good performance on the encapsulation efficiency of dexamethasone and siRNA. In an established RA mouse model, the delivered siRNA and dexamethasone respectively show arthritis inhibition effect, which may be attributed to the ability to selectively accumulate in inflammatory joints of arthritis mice. NF- $\mathrm{kB}$ siRNA effectively inhibits nuclear translocation of p65 and secretion of pro-inflammatory cytokines by activated macrophages. The combined action of siRNA and dexamethasone triggers the repolarization of macrophages from pro-inflammatory M1 type to anti-inflammatory M2 type (Wang et al., 2017).

Mi-RNA were essentially delivered in combination with other drugs. In one recent study (Hao et al., 2019) designed MTX-conjugated polymer hybrid micelles in which they incorporated miRNA-124. Micelles were formed by the association of MTX-Polyethylenimine-Linoleic acid conjugated and linoleic acid-modified methoxy-polyethylene glycol. miRNA-124 was associated by charge interactions. Complexes exhibited folate receptor-mediated uptake in activated RAW264.7 cells. miRNA was able to escape from the endosome and down-regulate nuclear factor of activated $\mathrm{T}$ cells cytoplasmic1 (NFATc1). MTX-conjugated polymer hybrid micelles/miR-124 complexes accumulated in inflamed joints of AIA rats and showed superior therapeutic efficacy through both anti-inflammatory effect and direct bone protective effect. Combination of miR-124 and MTX in these micelles induced disease remission. In another very recent study, ketoprofen was associated with microRNA-within PLGA microspheres and administrated locally to AIA in rats. In vivo pharmacodynamic experimental results indicated ketoprofen in co-loaded microspheres could significantly reduce inflammation of the joints and miRNA-124 in the microspheres could reduce bone damage. In addition, ketoprofen and miR-124 co-loaded PLGA microspheres had a remarkably advanced activity over the delivery of either miR-124 or ketoprofen in suppressing AIA in rats. Results of western blot and immunohistochemistry revealed that miR-124 could reduce the level of receptor activator of NF- $\mathrm{kB}$ ligand These results although provided by local administration suggested co-delivery of ketoprofen and miR-124 could achieve synergistic effects on preventing inflammation and bone damage caused by RA (C. Yu et al., 2018).

\section{Challenges and perspective on the nanomedicine development for RA.}

Over the past decades, the treatment of RA has achieved significant progress but no cure for complete remission is today available. The goal of the treatment of RA focuses on relieving inflammation, decreasing pain, and improving the overall function to promote better life quality of patients. As introduced above, NSAIDs, DMARDs, and GCs are widely used clinically to reach this goal. However, some issue limited their clinical application including poor efficacy, 
side effects, low responsiveness, and high costs, fostering research to solve these drawbacks.

Owing to nanotechnologies, the pharmacokinetics of GCs and the stability of siRNA were improved, but there are still many challenges that cannot be ignored:

1. The safety of the delivery system is, of course, a source of concern. The materials used to produce the delivery system should not induce additional toxicity.

2. The strong uptake of nanotechnologies by the monocyte phagocytic system should be reduced in order to deliver as much as possible drugs to the inflamed region.

3. Maintaining nanotechnologies stability in biological fluids and non-inflammatory tissues to avoid drug leakage is also an important factor to be taken into account.

4. At present, passive targeting of nanoparticles due to their extravasation at inflamed sites is not particularly satisfactory, and ways to improve the targeted delivery efficiency still needs optimization.

Currently, different types of delivery systems are being investigated taking into consideration the above concerns. Developing a suitable delivery system for combining the delivery of several drugs could lead to stronger anti-inflammatory effects and help to reduce the doses and side effects. To achieve a better therapeutic effect, drug accumulation in specific areas can be further enhanced by modifying the delivery system with targeting ligands. Based on the specific physiological microenvironment of arthritic tissues, drug release by stimuli-responsive delivery systems is also a good approach to reduce drug side effects in other tissues. As tumor microenvironment possesses many similarities with inflammatory tissue microenvironment such as hypoxia, acidosis, and neovascularization, the treatment of RA could benefit from advances in cancer treatment using nanotechnologies.

\section{Conclusions}

In conclusion, we here show that the use of nanomedicines allows to considerably improve the delivery of either GCs and nucleic acids. Attempts to formulate both drugs in the same carrier is appealing but needs to be further investigated. siRNA delivery was mostly demonstrated in animal models with the aim of reducing TNF- $\alpha$ levels which plays a major role in RA. Only a few experiments have described the potentialities of using miRNA or Anti-miRNA. We, however, believe that in the future they will be much space in designing smart delivery systems for these molecules. Among the different nanomedicines, it is hard today to have a clear view of which one would be more efficient. Many were used with success on the same murine models, therefore

only further studies, among which toxicological studies, will allow to sort out the most optimal system able to move on with clinical studies.

\section{Acknowledgments}

Zhibo Yu was supported by the China Scholarship Council. We acknowledge Agence Nationale de la Recherche throughTANGO project, ANR-16-CE09-0020-01 for financial support. 


\section{Conflict of interest}

The authors have declared no conflicts of interest in this article. 
Table 1: Applications of nanomedicine-loaded glucocorticoids in the treatment of rheumatoid arthritis (AIA: Adjuvant-induced arthritis; CIA: Collagen-induced arthritis; LPS: Lipopolysaccharide)

\begin{tabular}{|c|c|c|c|c|}
\hline Glucocorticoid & Formulation & Animal model & Results & Reference \\
\hline Dexamethasone & Liposomes conventional & AIA/Rat & $\begin{array}{l}\text { - Suppression of both chronic inflammation and joint } \\
\text { destruction compared to free drug. }\end{array}$ & $\begin{array}{l}\text { (Rauchhaus et } \\
\text { al., 2009a) }\end{array}$ \\
\hline Prednisolone palmitate & Liposomes conventional & $\begin{array}{c}\lambda \text {-carrageenin } \\
\text { paw edema } \\
\text { test/Rat }\end{array}$ & $\begin{array}{l}\text { - Higher anti-inflammatory activity than prednisolone } \\
\text { hemisuccinate demonstrated by edema inhibition. }\end{array}$ & $\begin{array}{l}\text { (Hong Kee et } \\
\text { al., 1988) }\end{array}$ \\
\hline $\begin{array}{l}\text { Dexamethasone } \\
\text { phosphate }\end{array}$ & Liposomes conventional & AIA/Rat & $\begin{array}{l}\text { - Supression of arthritis evidences by histological signs } \\
\text { and and production of IL-1 and IL-6 by peritoneal } \\
\text { macrophages. } \\
\text { - Strong and long-lasting suppression } \\
\text { - Reduction of the dose and/or frequency required to treat } \\
\text { AA. } \\
\text { - Limited side-effects. }\end{array}$ & $\begin{array}{l}\text { (Anderson et } \\
\text { al., 2010) }\end{array}$ \\
\hline Prednisolone acetate & Liposomes conventional & Healthy Rat & $\begin{array}{l}\text { - Zero-order release. } \\
\text { - Pharmacokinetic superiority for the liposomal } \\
\text { prednisolone acetate above the free prednisolone. }\end{array}$ & $\begin{array}{l}\text { (Hosseini et } \\
\text { al., 2016) }\end{array}$ \\
\hline $\begin{array}{l}\text { Dexamethasone } \\
\text { phosphate }\end{array}$ & Liposomes conventional & CIA/Mice & $\begin{array}{l}\text { - Liposomal DXM-P, but not free drug, resulted in a } \\
\text { persistent anti-inflammatory effect. } \\
\text { - Comparable clinical benefit was achieved with a single } \\
\text { administration of } 4 \mathrm{mg} / \mathrm{kg} \text { liposomal DXM-P or daily } \\
\text { administrations of } 1.6 \mathrm{mg} / \mathrm{kg} \text { free drug for at least } 7 \text { days. }\end{array}$ & $\begin{array}{l}\text { (Rauchhaus et } \\
\text { al., 2009b) }\end{array}$ \\
\hline $\begin{array}{l}\text { Prednisolone } \\
\text { phosphate }\end{array}$ & Liposomes Stealth ${ }^{\circledR}$ & AIA/Rat & $\begin{array}{l}\text { - A single injection of } 10 \mathrm{mg} / \mathrm{kg} \text { resulted in complete } \\
\text { remission of the inflammatory response for almost a } \\
\text { week. } \\
\text { - Preferential glucocorticoid delivery to the inflamed joint. }\end{array}$ & $\begin{array}{l}\text { (Metselaar et } \\
\text { al., 2003) }\end{array}$ \\
\hline
\end{tabular}




\begin{tabular}{|c|c|c|c|c|}
\hline $\begin{array}{l}\text { Prednisolone } \\
\text { phosphate }\end{array}$ & Liposomes Stealth $®$ & AIA/Mice & $\begin{array}{l}\text { - A single injection of prednisolone phosphate liopsomes } \\
\text { showed a pronounced suppression of synovial immune } \\
\text { cell infiltration compared to control. } \\
\text { - Supression of IL- } 1 \beta \text { and metalloproteases. } \\
\text { - Liposomal prednisolone suppresses destruction of the } \\
\text { cartilage matrix. }\end{array}$ & $\begin{array}{l}\text { (Hofkens et } \\
\text { al., 2011) }\end{array}$ \\
\hline $\begin{array}{l}\text { Methyl prednisolone } \\
\text { hemisuccinate }\end{array}$ & Liposomes Stealth® & $\begin{array}{l}\text { CIA/Rat \& } \\
\text { Beagle Dog }\end{array}$ & $\begin{array}{l}\text { - Controlled drug release during systemic circulation and } \\
\text { in inflamed paws. }\end{array}$ & $\begin{array}{c}\text { (Avnir et al., } \\
\text { 2008) }\end{array}$ \\
\hline $\begin{array}{l}\text { Prednisolone, } \\
\text { dexamethasone, } \\
\text { budesonide }\end{array}$ & Liposomes Stealth ${ }^{\circledR}$ & AIA/Rat & $\begin{array}{l}\text { - Small-sized long-circulating liposomes r of } \\
\text { dexamethasone or budesonide demonstrated higher } \\
\text { potency than prednisolone with however more } \\
\text { side-effects due to the amount of sustained free drug } \\
\text { released }\end{array}$ & $\begin{array}{l}\text { (Van den } \\
\text { Hoven et al., } \\
\text { 2011) }\end{array}$ \\
\hline $\begin{array}{l}\text { Dexamethasone } \\
\text { phosphate }\end{array}$ & $\begin{array}{l}\text { RGD-bearing Stealth }{ }^{\circledR} \\
\text { liposomes }\end{array}$ & $\begin{array}{l}\text { AIA/LPS/Rat } \\
\text { inflammation }\end{array}$ & $\begin{array}{l}\text { - One single intravenous injection resulted in a strong and } \\
\text { long- lasting antiarthritic effect. }\end{array}$ & $\begin{array}{c}\text { (Koning et al., } \\
\text { 2006) }\end{array}$ \\
\hline Betamethasone & $\begin{array}{l}\text { Folate-bearing Stealth }{ }^{\circledR} \\
\text { liposomes }\end{array}$ & AIA/Rat & $\begin{array}{l}\text { - Targeted liposomes selectively accumulated in arthritic } \\
\text { rat paws in a larger extent than non targeted. } \\
\text { - Treated animals exhibited less paw swelling, lower } \\
\text { arthritis scores, a reduction in bone erosion, less } \\
\text { splenomegaly and better maintenance of body weight } \\
\text { when compared with untreated or non-targeted } \\
\text { bethamethasone-containing liposome groups. }\end{array}$ & $\begin{array}{l}\text { (Poh et al., } \\
\text { 2017) }\end{array}$ \\
\hline $\begin{array}{l}\text { Dexamethasone } \\
\text { palmitate }\end{array}$ & $\begin{array}{l}\text { Sialic acid modified } \\
\quad \text { liposomes }\end{array}$ & AIA rat & $\begin{array}{l}\text { - Sialic-acid-modified liposomes provided a greater degree } \\
\text { of accumulation in the joints and a stronger } \\
\text { anti-inflammatory effect in terms of RA suppression. }\end{array}$ & $\begin{array}{l}\text { (Hu et al., } \\
\text { 2019) }\end{array}$ \\
\hline Dexamethasone & $\begin{array}{l}\text { Micelles of amphipathic } \\
\text { poly (ethylene }\end{array}$ & AIA/Rat & $\begin{array}{l}\text { - Long time circulation in blood and preferential } \\
\text { accumulation in inflamed joints. }\end{array}$ & $\begin{array}{l}\text { (Wang et al., } \\
\text { 2016) }\end{array}$ \\
\hline
\end{tabular}




\begin{tabular}{|c|c|c|c|c|}
\hline & $\begin{array}{l}\text { glycol)-block-poly } \\
\text { (E-caprolactone) }\end{array}$ & & & \\
\hline Dexamethasone & $\begin{array}{c}\text { Micelles made of } \\
\text { dexamethasone attached to } \\
\text { the side chains of a } \\
\text { wheat-like polyethylene } \\
\text { glycol (PEG) derivative via } \\
\text { an acid-responsive linker }\end{array}$ & AIA/Rat & $\begin{array}{l}\text { - Improved pharmacokinetics properties } \\
\text { - Preferential release in acidic arthritic joints } \\
\text { - Significant reduction of the arthritis score }\end{array}$ & $\begin{array}{l}\text { (Wang et al., } \\
\text { 2019) }\end{array}$ \\
\hline $\begin{array}{l}\text { Betamethasone } \\
\text { disodium } \\
\text { 21-phosphate }\end{array}$ & $\begin{array}{l}\text { Nanoparticles of Poly } \\
\text { (lactide-co-glycolide) and } \\
\text { poly(lactide-co-glycolide)- } \\
\text { PEG }\end{array}$ & $\begin{array}{c}\text { AIA/Rat } \\
\text { Anti-type II } \\
\text { collagen } \\
\text { antibody-induced } \\
\text { arthritis /Mice }\end{array}$ & $\begin{array}{l}\text { - Particles of } 115 \mathrm{~nm} \text {, exhibited highest anti-inflammatory } \\
\text { activity than those of } 45 \mathrm{~nm} \text {. } \\
\text { - High accumulation of the stealth nanoparticles in } \\
\text { inflamed joints. }\end{array}$ & $\begin{array}{l}\text { (Ishihara et } \\
\text { al., 2009) }\end{array}$ \\
\hline Dexamethasone & $\begin{array}{l}\text { Conjugate of } \\
\text { dexamethasone- } \\
\text { Polyethylene glycol }\end{array}$ & AIA/Rat & $\begin{array}{l}\text { - Conjugate administration provided more than } 15 \text { days } \\
\text { amelioration of ankle joint inflammation. }\end{array}$ & $\begin{array}{l}\text { ( Liu et al., } \\
\text { 2010) }\end{array}$ \\
\hline Dexamethasone & $\begin{array}{c}\text { Conjugate of } \\
\text { dexamethasone-N-(2-hydro } \\
\text { xypropyl) methacrylamide } \\
\text { copolymer } \\
\end{array}$ & AIA/Rat & $\begin{array}{l}\text { - Superior and longer-lasting anti-inflammatory effects. } \\
\text { - Greater bone and cartilage preservation. } \\
\text { - Selective accumulation due to potential } \\
\text { macrophage-mediated retention. }\end{array}$ & $\begin{array}{l}\text { (Wang et al., } \\
\text { 2007) }\end{array}$ \\
\hline Dexamethasone & $\begin{array}{l}\text { Conjugate of } \\
\text { dexamethasone-N-(2-hydro } \\
\text { xypropyl) methacrylamide } \\
\text { copolymer }\end{array}$ & CIA/Mice & $\begin{array}{l}\text { - Localization in the arthritis joints. } \\
\text { - Single dose of the conjugate and the dose equivalent of } \\
\text { free drug led to comparable clinical efficacy after } 30 \\
\text { days. }\end{array}$ & $\begin{array}{l}\text { (Quan et al., } \\
\text { 2016) }\end{array}$ \\
\hline Dexamethasone & $\begin{array}{l}\text { Nanoparticles made of } \\
\text { solely dexamethasone } \\
\text { palmitate and distearoyl }\end{array}$ & CIA/Mice & $\begin{array}{l}\text { - Improved pharmacokinetics properties } \\
\text { - Preferential release in acidic arthritic joints } \\
\text { - Significant reduction of the arthritis score }\end{array}$ & $\begin{array}{l}\text { (Lorscheider, } \\
\text { Tsapis, } \\
\text { ur-Rehman, et }\end{array}$ \\
\hline
\end{tabular}


Table 2: Applications of nanomedicine-loaded nucleic acids in the treatment of rheumatoid arthritis (CIA: Collagen-induced arthritis - AIA: Adjuvant-induced arthritis)

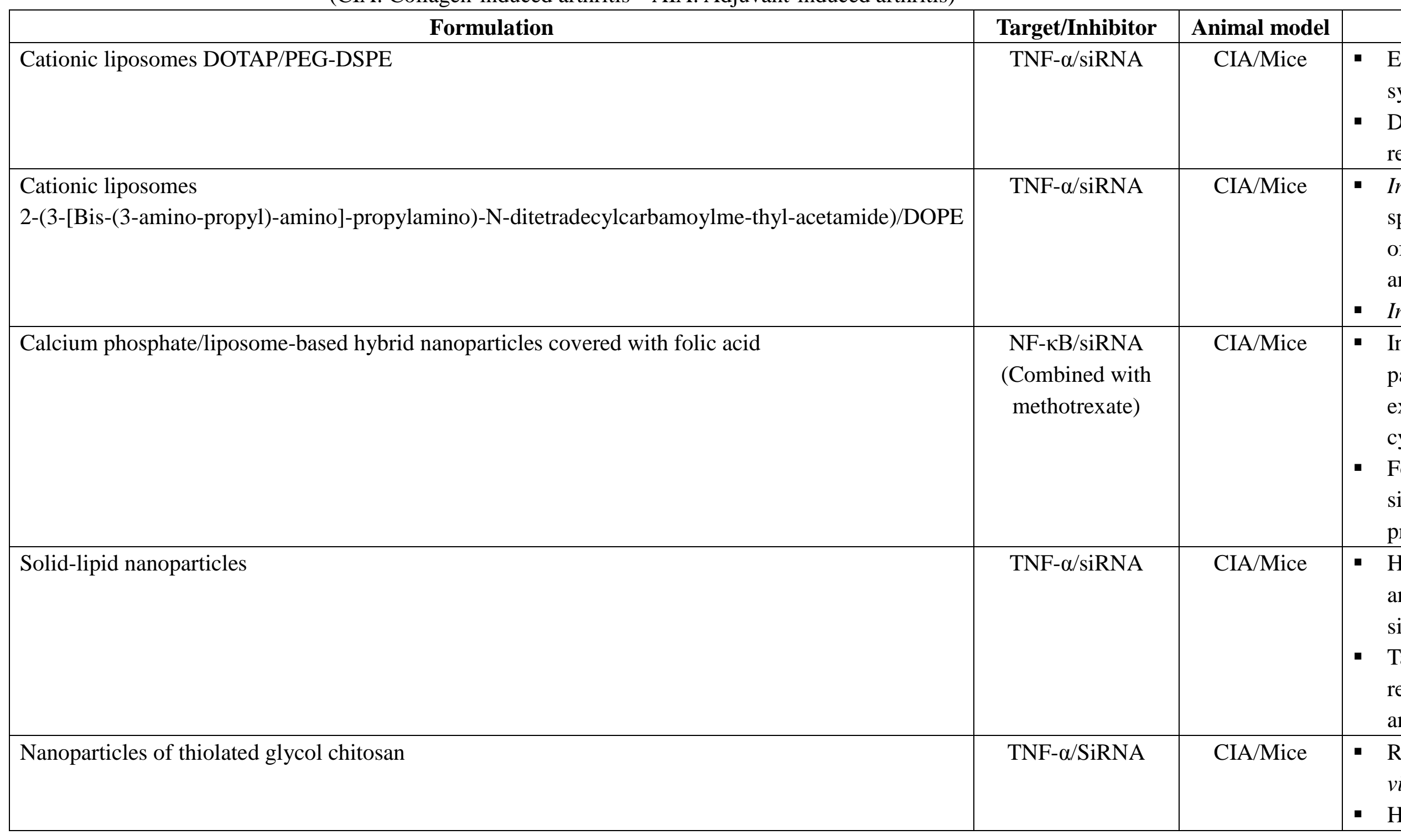




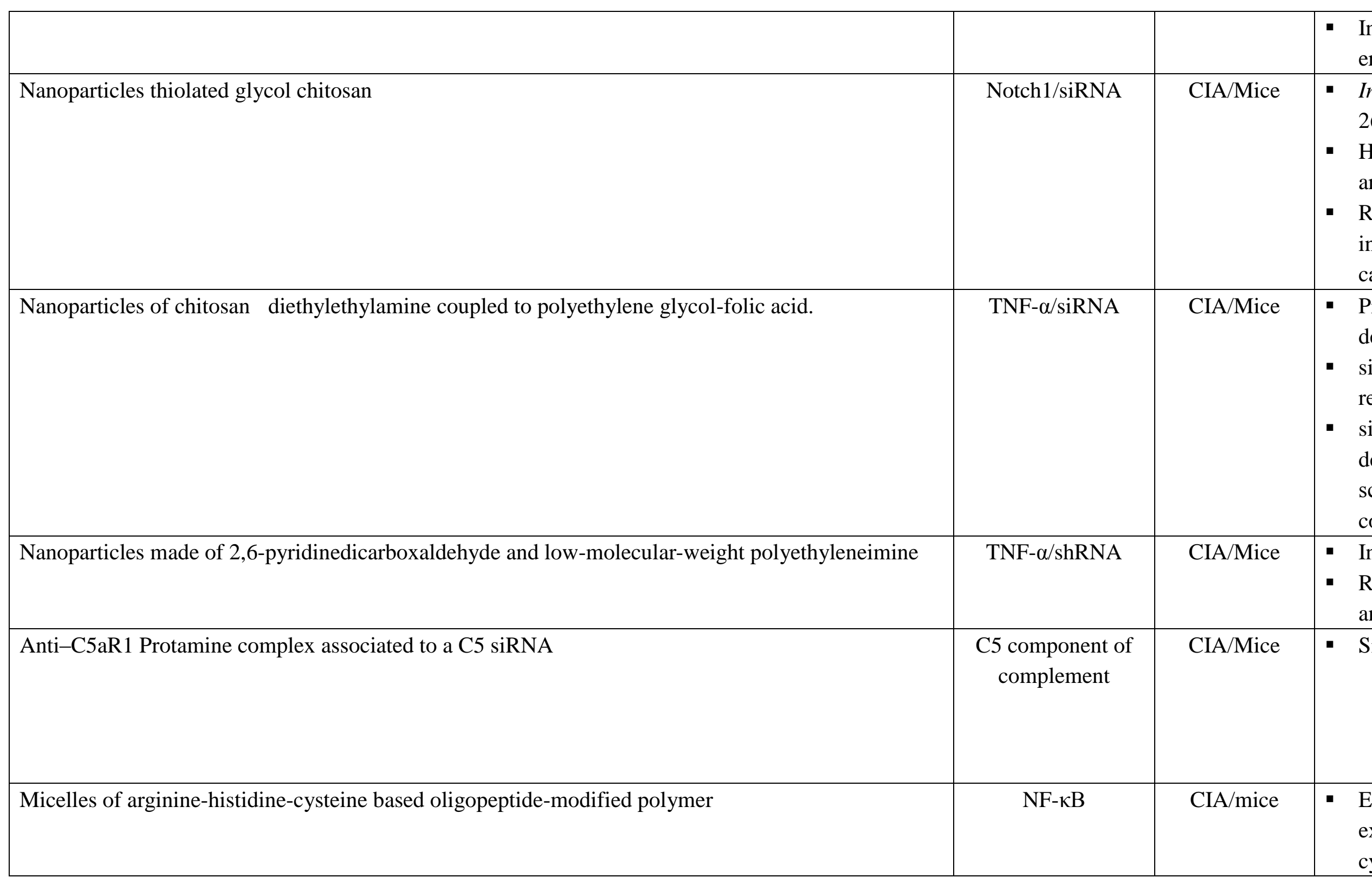




\begin{tabular}{|c|c|c|}
\hline Micelles of polyethylene glycol-poly $\varepsilon$-caprolactone-polyethylenimine & $\mathrm{NF}-\kappa \mathrm{B}$ & CIA/Mice \\
\hline DNA nanodrugs & $\mathrm{NF}-\kappa \mathrm{B}$ & AIA/Mice \\
\hline
\end{tabular}




\section{Reference}

Abbasi, E., Aval, S. F., Akbarzadeh, A., Milani, M., Nasrabadi, H. T., Joo, S. W., .. Pashaei-Asl, R. (2014). Dendrimers: synthesis, applications, and properties. Nanoscale Research Letters, 9(1), 247.

Af Klint, E., Grundtman, C., Engström, M., Catrina, A. I., Makrygiannakis, D., Klareskog, L., ... Ulfgren, A. K. (2005). Intraarticular glucocorticoid treatment reduces inflammation in synovial cell infiltrations more efficiently than in synovial blood vessels. Arthritis and Rheumatism, 52(12), 3880-3889. https://doi.org/10.1002/art.21488

Alconcel, S. N. S., Baas, A. S., \& Maynard, H. D. (2011). FDA-approved poly (ethylene glycol)-protein conjugate drugs. Polymer Chemistry, 2(7), 1442-1448.

Aldayel, A. M., O’Mary, H. L., Valdes, S. A., Li, X., Thakkar, S. G., Mustafa, B. E., \& Cui, Z. (2018). Lipid nanoparticles with minimum burst release of TNF- $\alpha$ siRNA show strong activity against rheumatoid arthritis unresponsive to methotrexate. Journal of Controlled Release, 283, 280-289. https://doi.org/10.1016/j.jconrel.2018.05.035

Alghasham, A., \& Rasheed, Z. (2014). Therapeutic targets for rheumatoid arthritis: Progress and promises. Autoimmunity, 47(2), 77-94.

Alivernini, S., Gremese, E., McSharry, C., Tolusso, B., Ferraccioli, G., McInnes, I. B., \& Kurowska-Stolarska, M. (2018). MicroRNA-155-at the critical interface of innate and adaptive immunity in arthritis. Frontiers in Immunology, 8, 1932. https://doi.org/10.3389/fimmu.2017.01932

Allen, T. M., Hansen, C., Martin, F., Redemann, C., \& Yau-Young, A. (1991). Liposomes containing synthetic lipid derivatives of poly(ethylene glycol) show prolonged circulation half-lives in vivo. BBA - Biomembranes, 1066(1), 29-36. https://doi.org/10.1016/0005-2736(91)90246-5

Alshaer, W., Hillaireau, H., Vergnaud, J., Mura, S., Deloménie, C., Sauvage, F., ... Fattal, E. (2018). Aptamer-guided siRNA-loaded nanomedicines for systemic gene silencing in CD-44 expressing murine triple-negative breast cancer model. Journal of Controlled Release, 271, 98-106. https://doi.org/10.1016/j.jconrel.2017.12.022

Amjad, M. W., Kesharwani, P., Amin, M. C. I. M., \& Iyer, A. K. (2017). Recent advances in the design, development, and targeting mechanisms of polymeric micelles for delivery of siRNA in cancer therapy. Progress in Polymer Science, 64, 154-181.

Amos, H., \& Kearns, K. E. (1963). Influence of bacterial ribonucleic acid on animal cells in culture: II. Protamine enhancement of RNA uptake. Experimental Cell Research, 32(1), 14-25.

Anderson, R., Franch, A., Castell, M., Perez-Cano, F. J., Bräuer, R., Pohlers, D., ... Kinne, R. W. (2010). Liposomal encapsulation enhances and prolongs the anti-inflammatory effects of water-soluble dexamethasone phosphate in experimental adjuvant arthritis. Arthritis Research and Therapy, 12(4), R147. https://doi.org/10.1186/ar3089 
Aouadi, M., Tesz, G. J., Nicoloro, S. M., Wang, M., Chouinard, M., Soto, E., .. Czech, M. P. (2009). Orally delivered siRNA targeting macrophage Map4k4 suppresses systemic inflammation. Nature, 458(7242), 1180-1184. https://doi.org/10.1038/nature07774

Apparailly, F., \& Jorgensen, C. (2013). siRNA-based therapeutic approaches for rheumatic diseases. Nature Reviews Rheumatology, 9(1), 56.

Arima, H., Aramaki, Y., \& Tsuchiya, S. (1997). Effects of oligodeoxynucleotides on the physicochemical characteristics and cellular uptake of liposomes. Journal of Pharmaceutical Sciences. https://doi.org/10.1021/js9603865

Avnir, Y., Ulmansky, R., Wasserman, V., Even-Chen, S., Broyer, M., Barenholz, Y., \& Naparstek, Y. (2008). Amphipathic weak acid glucocorticoid prodrugs remote-loaded into sterically stabilized nanoliposomes evaluated in arthritic rats and in a Beagle dog: a novel approach to treating autoimmune arthritis. Arthritis and Rheumatism, 58(1), 119-129. https://doi.org/10.1002/art.23230

Bala, S., Marcos, M., Kodys, K., Csak, T., Catalano, D., Mandrekar, P., \& Szabo, G. (2011). Up-regulation of microRNA-155 in macrophages contributes to increased Tumor Necrosis Factor $\alpha(\mathrm{TNF} \alpha)$ production via increased mRNA half-life in alcoholic liver disease. Journal of Biological Chemistry, 286(2), 1436-1444. https://doi.org/10.1074/jbc.M110.145870

Bartel, D. P. (2004). MicroRNAs: Genomics, Biogenesis, Mechanism, and Function. Cell, 116(2), 281-297. https://doi.org/10.1016/S0092-8674(04)00045-5

Bauer, B. J., \& Amis, E. J. (2001). Characterization of Dendritically Branched Polymers by Small Angle Neutron Scattering (SANS), Small Angle X- Ray Scattering (SAXS) and Transmission Electron Microscopy (TEM). Dendrimers and Other Dendritic Polymers, 255-284.

Behlke, M. A. (2008). Chemical modification of siRNAs for in vivo use. Oligonucleotides, 18(4), $305-320$.

Biswas, S., \& Torchilin, V. (2013). Dendrimers for siRNA delivery. Pharmaceuticals, 6(2), $161-183$.

Blüml, S., Bonelli, M., Niederreiter, B., Puchner, A., Mayr, G., Hayer, S., ... Redlich, K. (2011). Essential role of microRNA-155 in the pathogenesis of autoimmune arthritis in mice. Arthritis \& Rheumatism, 63(5), 1281-1288. https://doi.org/10.1002/art.30281

Boeckle, S., von Gersdorff, K., van der Piepen, S., Culmsee, C., Wagner, E., \& Ogris, M. (2004). Purification of polyethylenimine polyplexes highlights the role of free polycations in gene transfer. The Journal of Gene Medicine: A Cross - disciplinary Journal for Research on the Science of Gene Transfer and Its Clinical Applications, 6(10), 1102-1111.

Bohr, A., Tsapis, N., Andreana, I., Chamarat, A., Foged, C., Delomenie, C., ... Fattal, E. (2017). Anti-Inflammatory Effect of Anti-TNF- $\alpha$ SiRNA Cationic Phosphorus Dendrimer Nanocomplexes Administered Intranasally in a Murine Acute Lung Injury Model. Biomacromolecules, 18(8), 2379-2388. https://doi.org/10.1021/acs.biomac.7b00572 
Brennan, F., Jackson, A., Chantry, D., Maini, R., \& Feldmann, M. (1989). Inhibitory effect of TNF-alpha antibodies on synovial cell IL1 production in rheumatoid arthritis. The Lancet, 334(8657), 244-247. https://doi.org/https://doi.org/10.1016/S0140-6736(89)90430-3

Buch, M. H., Bingham, S. J., Bryer, D., \& Emery, P. (2007). Long-term infliximab treatment in rheumatoid arthritis: subsequent outcome of initial responders. Rheumatology, 46(7), 1153-1156. https://doi.org/10.1093/rheumatology/kem075

Burmester, G. R., Feist, E., \& Dörner, T. (2014). Emerging cell and cytokine targets in rheumatoid arthritis. Nature Reviews Rheumatology, 10(2), 77-88. https://doi.org/10.1038/nrrheum.2013.168

Byk, G., Dubertret, C., Escriou, V., Frederic, M., Jaslin, G., Rangara, R., ... Scherman, D. (1998). Synthesis, Activity, and Structure-Activity Relationship Studies of Novel Cationic Lipids for DNA Transfer. Journal of Medicinal Chemistry, 41(2), 224-235. https://doi.org/10.1021/jm9704964

Caminade, A.-M., Ouali, A., Laurent, R., Turrin, C.-O., \& Majoral, J.-P. (2015). The dendritic effect illustrated with phosphorus dendrimers. Chemical Society Reviews, 44(12), 3890-3899.

Canal, F., Sanchis, J., \& Vicent, M. J. (2011). Polymer-drug conjugates as nano-sized medicines. Current Opinion in Biotechnology, 22(6), 894-900.

Chatzidionysiou, K., Emamikia, S., Nam, J., Ramiro, S., Smolen, J., van der Heijde, D., ... Landewé, R. (2017). Efficacy of glucocorticoids, conventional and targeted synthetic disease-modifying antirheumatic drugs: a systematic literature review informing the 2016 update of the EULAR recommendations for the management of rheumatoid arthritis. Annals of the Rheumatic Diseases, 76(6), 1102-1107. https://doi.org/10.1136/annrheumdis-2016-210711

Chen, J. Q., Papp, G., Szodoray, P., \& Zeher, M. (2016). The role of microRNAs in the pathogenesis of autoimmune diseases. Autoimmunity Reviews, 15(12), 1171-1180. https://doi.org/10.1016/j.autrev.2016.09.003

Dadoun, S., Zeboulon-Ktorza, N., Combescure, C., Elhai, M., Rozenberg, S., Gossec, L., \& Fautrel, B. (2013). Mortality in rheumatoid arthritis over the last fifty years: Systematic review and meta-analysis. Joint Bone Spine, 80(1), 29-33. https://doi.org/10.1016/j.jbspin.2012.02.005

Dang, Q., Yang, F., Lei, H., Liu, X., Yan, M., Huang, H., ... Li, Y. (2017). Inhibition of microRNA-34a ameliorates murine collagen-induced arthritis. Experimental and Therapeutic Medicine, 14(2), 1633-1639. https://doi.org/10.3892/etm.2017.4708

De Rosa, G., Quaglia, F., La Rotonda, M. I., Appel, M., Alphandary, H., \& Fattal, E. (2002). Poly(lactide-co-glycolide) microspheres for the controlled release of oligonucleotide/polyethylenimine complexes. Journal of Pharmaceutical Sciences, 91(3), 790-799. https://doi.org/10.1002/jps.10063

Deriu, M. A., Tsapis, N., Noiray, M., Grasso, G., El Brahmi, N., Mignani, S., ... Danani, A. 
(2018). Elucidating the role of surface chemistry on cationic phosphorus dendrimer-siRNA complexation. Nanoscale, 10(23), 10952-10962.

Dolati, S., Sadreddini, S., Rostamzadeh, D., Ahmadi, M., Jadidi-Niaragh, F., \& Yousefi, M. (2016). Utilization of nanoparticle technology in rheumatoid arthritis treatment. Biomedicine and Pharmacotherapy, $\quad 30-41$. https://doi.org/10.1016/j.biopha.2016.03.004

Downey, C. (2016). Serious infection during etanercept, infliximab and adalimumab therapy for rheumatoid arthritis: A literature review. International Journal of Rheumatic Diseases, 19(6), 536-550. https://doi.org/10.1111/1756-185X.12659

Duan, H., Yang, P., Fang, F., Ding, S., \& Xiao, W. (2014). CCR5 small interfering RNA ameliorated joint inflammation in rats with adjuvant-induced arthritis. Immunology Letters, 162(2), 258-263. https://doi.org/10.1016/J.IMLET.2014.09.018

Duan, W., \& Li, H. (2018). Combination of NF-kB targeted siRNA and methotrexate in a hybrid nanocarrier towards the effective treatment in rheumatoid arthritis. Journal of Nanobiotechnology, 16(1), 58. https://doi.org/10.1186/s12951-018-0382-X

Dzmitruk, V., Apartsin, E., Ihnatsyeu-Kachan, A., Abashkin, V., Shcharbin, D., \& Bryszewska, M. (2018). Dendrimers show promise for siRNA and microrna therapeutics. Pharmaceutics, 10(3), 126. https://doi.org/10.3390/pharmaceutics 10030126

Elmesmari, A., Fraser, A. R., Wood, C., Gilchrist, D., Vaughan, D., Stewart, L., ... Kurowska-Stolarska, M. (2016). MicroRNA-155 regulates monocyte chemokine and chemokine receptor expression in Rheumatoid Arthritis. Rheumatology (United Kingdom), 55(11), 2056-2065. https://doi.org/10.1093/rheumatology/kew272

Esteller, M. (2011). Non-coding RNAs in human disease. Nature Reviews Genetics, 12(12), 861-874. https://doi.org/10.1038/nrg3074

Evangelatos, G., Fragoulis, G. E., Koulouri, V., \& Lambrou, G. I. (2019). MicroRNAs in rheumatoid arthritis: From pathogenesis to clinical impact. Autoimmunity Reviews, 18(11), 102391. https://doi.org/10.1016/j.autrev.2019.102391

Fan, T., Zhong, F., Liu, R., Chen, Y. H., Wang, T., \& Ruan, Q. (2018). siRNA-mediated c-Rel knockdown ameliorates collagen-induced arthritis in mice. International Immunopharmacology, 56, 9-17. https://doi.org/10.1016/J.INTIMP.2018.01.010

Feng, X., \& Chen, Y. (2018). Drug delivery targets and systems for targeted treatment of rheumatoid arthritis. $J$ Drug Target, 26(10), 845-857. https://doi.org/10.1080/1061186X.2018.1433680

Ferenc, M., Pedziwiatr-Werbicka, E., Nowak, K., Klajnert, B., Majoral, J.-P., \& Bryszewska, M. (2013). Phosphorus dendrimers as carriers of siRNA - characterisation of dendriplexes. Molecules, 18(4), 4451-4466.

Ferreira, J. F., Ahmed Mohamed, A. A., \& Emery, P. (2016). Glucocorticoids and Rheumatoid Arthritis. Rheumatic Disease Clinics of North America. https://doi.org/10.1016/j.rdc.2015.08.006 
Filková, M., Aradi, B., Šenolt, L., Ospelt, C., Vettori, S., Mann, H., ... Jüngel, A. (2014). Association of circulating miR-223 and miR-16 with disease activity in patients with early rheumatoid arthritis. Annals of the Rheumatic Diseases, 73(10), 1898-1904. https://doi.org/10.1136/ANNRHEUMDIS-2012-202815

Firestein, G. S. (1999). Starving the synovium: Angiogenesis and inflammation in rheumatoid arthritis. Journal of Clinical Investigation, 103(1), 3-4. https://doi.org/10.1172/JCI5929

Fischer, D., von Harpe, A., Kunath, K., Petersen, H., Li, Y., \& Kissel, T. (2002). Copolymers of ethylene imine and $\mathrm{N}$-(2-hydroxyethyl)-ethylene imine as tools to study effects of polymer structure on physicochemical and biological properties of DNA complexes. Bioconjugate Chemistry, 13(5), 1124-1133.

Gauthier, A., Fisch, A., Seuwen, K., Baumgarten, B., Ruffner, H., Aebi, A., ... Ludwig, M. G. (2018). Glucocorticoid-loaded liposomes induce a pro-resolution phenotype in human primary macrophages to support chronic wound healing. Biomaterials, 178, 481-495. https://doi.org/10.1016/j.biomaterials.2018.04.006

Gibofsky, A. (2014). Epidemiology, pathophysiology, and diagnosis of rheumatoid arthritis: A Synopsis. Am J Manag Care, $20(7$ Suppl), S128-35. Retrieved from https://www.ncbi.nlm.nih.gov/pubmed/25180621

Gierut, A., Perlman, H., \& Pope, R. M. (2010). Innate immunity and rheumatoid arthritis. Rheum Dis Clin North Am, 36(2), 271-296. https://doi.org/10.1016/j.rdc.2010.03.004

Gómez-Gaete, C., Fattal, E., Silva, L., Besnard, M., \& Tsapis, N. (2008). Dexamethasone acetate encapsulation into Trojan particles. Journal of Controlled Release, 128(1), 41-49.

Gómez-Gaete, C., Tsapis, N., Besnard, M., Bochot, A., \& Fattal, E. (2007). Encapsulation of dexamethasone into biodegradable polymeric nanoparticles. International Journal of Pharmaceutics, 331(2), 153-159. https://doi.org/10.1016/j.ijpharm.2006.11.028

Hao, F., Lee, R. J., Zhong, L., Dong, S., Yang, C., Teng, L., ... Teng, L. (2019). Hybrid micelles containing methotrexate-conjugated polymer and co-loaded with microRNA-124 for rheumatoid arthritis therapy. Theranostics, 9(18), 5282-5297. https://doi.org/10.7150/thno.32268

Haussecker, D. (2014). Current issues of RNAi therapeutics delivery and development. Journal of Controlled Release, 195, 49-54.

Hayder, M., Poupot, M., Baron, M., Nigon, D., Turrin, C. O., Caminade, A. M., ... Davignon, J. L. (2011). A phosphorus-based dendrimer targets inflammation and osteoclastogenesis in experimental arthritis. Science Translational Medicine, 3(81), 81ra35. https://doi.org/10.1126/scitranslmed.3002212

Hazlewood, G. S., Barnabe, C., Tomlinson, G., Marshall, D., Devoe, D., \& Bombardier, C. (2016). Methotrexate monotherapy and methotrexate combination therapy with traditional and biologic disease modifying antirheumatic drugs for rheumatoid arthritis: Abridged cochrane Systematic review and network meta-analysis. BMJ (Online), 353. https://doi.org/10.1136/bmj.i1777 
Higaki, M., Ishihara, T., Izumo, N., Takatsu, M., \& Mizushima, Y. (2005). Treatment of experimental arthritis with poly(D, L-lactic/glycolic acid) nanoparticles encapsulating betamethasone sodium phosphate. Annals of the Rheumatic Diseases, 64(8), 1132-1136. https://doi.org/10.1136/ard.2004.030759

Hochberg, Z. (2004). Glucocorticoid Withdrawal Syndrome. The Endocrinologist, 14(3), 152-160. Retrieved from https://journals.lww.com/theendocrinologist/Fulltext/2004/05000/Glucocorticoid_Withdraw al_Syndrome.10.aspx

Hofkens, W., Storm, G., Van Den Berg, W. B., \& Van Lent, P. L. (2011). Liposomal targeting of glucocorticoids to the inflamed synovium inhibits cartilage matrix destruction during murine antigen-induced arthritis. International Journal of Pharmaceutics, 416(2), 486-492. https://doi.org/10.1016/j.ijpharm.2011.02.060

Hong Kee, S., Hack Joo, K., Hyun Pyo, K., Lee, H. J., \& Si Myung, B. (1988). Liposomes with anti-inflammatory steroid prednisolone palmitate. Drug Development and Industrial Pharmacy, 4(6), 765-777.

Hosseini, S. H., Maleki, A., Eshraghi, H. R., \& Hamidi, M. (2016). Preparation and in vitro/pharmacokinetic/pharmacodynamic evaluation of a slow-release nano-liposomal form of prednisolone. Drug Delivery, 23(8), 3008-3016. https://doi.org/10.3109/10717544.2016.1138341

Howard, K. A. (2009). Delivery of RNA interference therapeutics using polycation-based nanoparticles. Advanced Drug Delivery Reviews, 61(9), 710-720.

Howard, K., Paludan, S., Behlke, M., Besenbacher, F., Deleuran, B., \& Kjems, J. (2009). Chitosan/siRNA Nanoparticle-mediated TNF- $\alpha$ Knockdown in Peritoneal Macrophages for Anti-inflammatory Treatment in a Murine Arthritis Model. Molecular Therapy, 17(1), 162-168. https://doi.org/10.1038/MT.2008.220

Hu, L., Luo, X., Zhou, S. L., Zhu, J. Y., Xiao, M. Y., Li, C., ... Song, Y. Z. (2019). Neutrophil-Mediated Delivery of Dexamethasone Palmitate-Loaded Liposomes Decorated with a Sialic Acid Conjugate for Rheumatoid Arthritis Treatment. Pharmaceutical Research, 36(7), 15. https://doi.org/10.1007/s11095-019-2609-4

$\mathrm{Hu}$, R., \& O’Connell, R. M. (2013). MicroRNA control in the development of systemic autoimmunity. Arthritis Research \& Therapy, 15(1), 202. https://doi.org/10.1186/ar4131

Hunter, A. C. (2006). Molecular hurdles in polyfectin design and mechanistic background to polycation induced cytotoxicity. Advanced Drug Delivery Reviews, 58(14), 1523-1531.

Inoue, H., Arai, Y., Kishida, T., Shin-Ya, M., Terauchi, R., Nakagawa, S., ... Kubo, T. (2014). Sonoporation-mediated transduction of siRNA ameliorated experimental arthritis using $3 \mathrm{MHz} \quad$ pulsed ultrasound. $\quad$ Ultrasonics, $\quad$ 54(3), 874-881. https://doi.org/10.1016/J.ULTRAS.2013.10.021

Ishihara, T., Kubota, T., Choi, T., \& Higaki, M. (2009). Treatment of experimental arthritis with stealth-type polymeric nanoparticles encapsulating betamethasone phosphate. The Journal 
of Pharmacology and Experimental Therapeutics, 329(2), 412-417. https://doi.org/10.1124/jpet.108.150276

Iwanaga, T., Shikichi, M., Kitamura, H., Yanase, H., \& Nozawa-Inoue, K. (2000). Morphology and functional roles of synoviocytes in the joint. Arch Histol Cytol, 63(1), 17-31.

Jackson, A. L., Bartz, S. R., Schelter, J., Kobayashi, S. V., Burchard, J., Mao, M., ... Linsley, P. S. (2003). Expression profiling reveals off-target gene regulation by RNAi. Nature Biotechnology, 21(6), 635-637. https://doi.org/10.1038/nbt831

Jackson, A. L., \& Linsley, P. S. (2010). Recognizing and avoiding siRNA off-target effects for target identification and therapeutic application. Nature Reviews Drug Discovery, 9(1), 57-67. https://doi.org/10.1038/nrd3010

Jansen, M. A. A., Klausen, L. H., Thanki, K., Lyngsø, J., Skov Pedersen, J., Franzyk, H., ... Zeng, X. (2019). Lipidoid-polymer hybrid nanoparticles loaded with TNF siRNA suppress inflammation after intra-articular administration in a murine experimental arthritis model. European Journal of Pharmaceutics and Biopharmaceutics, 142, 38-48. https://doi.org/10.1016/j.ejpb.2019.06.009

Jensen, L. B., Griger, J., Naeye, B., Varkouhi, A. K., Raemdonck, K., Schiffelers, R., ... Foged, C. (2012). Comparison of Polymeric siRNA Nanocarriers in a Murine LPS-Activated Macrophage Cell Line: Gene Silencing, Toxicity and Off-Target Gene Expression. Pharmaceutical Research, 29(3), 669-682. https://doi.org/10.1007/s11095-011-0589-0

Jhaveri, A. M., \& Torchilin, V. P. (2014). Multifunctional polymeric micelles for delivery of drugs and siRNA. Frontiers in Pharmacology, 5, 1-26. https://doi.org/10.3389/fphar.2014.00077

Joshi, N., Yan, J., Levy, S., Bhagchandani, S., Slaughter, K. V, Sherman, N. E., ... Karp, J. M. (2018). Towards an arthritis flare-responsive drug delivery system. Nature Communications, 9, 11. https://doi.org/10.1038/s41467-018-03691-1

Kanazawa, T., Endo, T., Arima, N., Ibaraki, H., Takashima, Y., \& Seta, Y. (2016). Systemic delivery of small interfering RNA targeting nuclear factor $\mathrm{\kappa B}$ in mice with collagen-induced arthritis using arginine-histidine-cysteine based oligopeptide-modified polymer nanomicelles. International Journal of Pharmaceutics, 515(1-2), 315-323. https://doi.org/10.1016/J.IJPHARM.2016.10.033

Kearsley-Fleet, L., Davies, R., De Cock, D., Watson, K. D., Lunt, M., Buch, M. H., ... Hyrich, K. L. (2018). Biologic refractory disease in rheumatoid arthritis: Results from the British Society for Rheumatology Biologics Register for Rheumatoid Arthritis. Annals of the

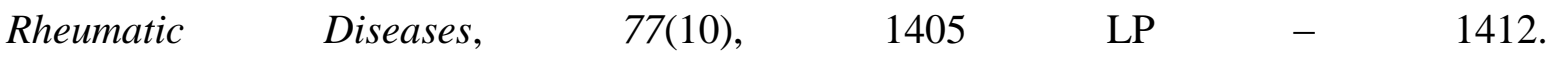
https://doi.org/10.1136/annrheumdis-2018-213378

Khodaverdi, E., Tayarani-Najaran, Z., Minbashi, E., Alibolandi, M., Hossein, J., Sepahi, S., ... Hadizadeh, F. (2019). Docetaxel-Loaded Mixed Micelles and Polymersomes Composed of Poly (caprolactone)-Poly (ethylene glycol) (PEG-PCL) and Poly (lactic acid)-Poly (ethylene glycol) (PEG-PLA): Preparation and In-vitro Characterization. Iranian Journal of 
Pharmaceutical Research, 18(1), 142-155.

Khoury, M., Escriou, V., Courties, G., Galy, A., Yao, R., Largeau, C., ... Apparailly, F. (2008). Efficient suppression of murine arthritis by combined anticytokine small interfering RNA lipoplexes. Arthritis and Rheumatism, 58(8), 2356-2367. https://doi.org/10.1002/art.23660

Khoury, M., Louis- Plence, P., Escriou, V., Noel, D., Largeau, C., Cantos, C., ... Apparailly, F. (2006). Efficient new cationic liposome formulation for systemic delivery of small interfering RNA silencing tumor necrosis factor $\alpha$ in experimental arthritis. Arthritis \& Rheumatism, 54(6), 1867-1877.

Kim, H. C., Kim, E., Ha, T. L., Lee, S. G., Lee, S. J., \& Jeong, S. W. (2017). Highly stable and reduction responsive micelles from a novel polymeric surfactant with a repeating disulfide-based gemini structure for efficient drug delivery. Polymer, 133, 102-109. https://doi.org/10.1016/j.polymer.2017.11.032

Kim, K. W., Cho, M. L., Lee, S. H., Oh, H. J., Kang, C. M., Ju, J. H., ... Kim, H. Y. (2007). Human rheumatoid synovial fibroblasts promote osteoclastogenic activity by activating RANKL via TLR-2 and TLR-4 activation. Immunol Lett, 110(1), 54-64. https://doi.org/10.1016/j.imlet.2007.03.004

Kim, M. J., Park, J.-S., Lee, S. J., Jang, J., Park, J. S., Back, S. H., .. Kim, K. (2015). Notch1 targeting siRNA delivery nanoparticles for rheumatoid arthritis therapy. Journal of Controlled Release, 216, 140-148. https://doi.org/10.1016/J.JCONREL.2015.08.025

Klibanov, A. L., Maruyama, K., Torchilin, V. P., \& Huang, L. (1990). Amphipathic polyethyleneglycols effectively prolong the circulation time of liposomes. FEBS Letters, 268(1), 235-237. https://doi.org/10.1016/0014-5793(90)81016-H

Knudsen, K. B., Northeved, H., Pramod Kumar, E. K., Permin, A., Gjetting, T., Andresen, T. L., .. Roursgaard, M. (2015). In vivo toxicity of cationic micelles and liposomes. Nanomedicine: Nanotechnology, Biology, and Medicine, 11(2). https://doi.org/10.1016/j.nano.2014.08.004

Komano, Y., Yagi, N., Onoue, I., Kaneko, K., Miyasaka, N., \& Nanki, T. (2011). Arthritic Joint-Targeting siRNA Encapsulated Liposome: Implication for Treatment Strategy for Rheumatoid Arthritis. The Journal of Pharmacology and Experimental Therapeutics, 340(1), 109-113. https://doi.org/10.1124/jpet.111.185884

Koning, G. A., Schiffelers, R. M., Wauben, M. H. M., Kok, R. J., Mastrobattista, E., Molema, G., ... Storm, G. (2006). Targeting of angiogenic endothelial cells at sites of inflammation by dexamethasone phosphate-containing RGD peptide liposomes inhibits experimental arthritis. Arthritis \& Rheumatism, 54(4), 1198-1208.

Koo, O. M. Y., Rubinstein, I., \& Önyüksel, H. (2011). Actively targeted low-dose camptothecin as a safe, long-acting, disease-modifying nanomedicine for rheumatoid arthritis. Pharmaceutical Research, 28(4), 776-787.

Kopeček, J. (2013). Polymer-drug conjugates: origins, progress to date and future directions. Advanced Drug Delivery Reviews, 65(1), 49-59. 
Krakovičová, H., Etrych, T., \& Ulbrich, K. (2009). HPMA-based polymer conjugates with drug combination. European Journal of Pharmaceutical Sciences, 37(3-4), 405-412.

Laine, L. (2002). The gastrointestinal effects of nonselective NSAIDs and COX-2-selective inhibitors. Seminars in Arthritis and Rheumatism, 32(3), 25-32. https://doi.org/10.1053/SARH.2002.37217

Layzer, J. M., McCaffrey, A. P., Tanner, A. K., Huang, Z., Kay, M. A., \& Sullenger, B. A. (2004). In vivo activity of nuclease-resistant siRNAs. RNA (New York, N.Y.), 10(5), 766-771. https://doi.org/10.1261/rna.5239604

Lee, S. J., Lee, A., Hwang, S. R., Park, J.-S., Jang, J., Huh, M. S., ... Kim, K. (2014a). TNF- $\alpha$ Gene Silencing Using Polymerized siRNA/Thiolated Glycol Chitosan Nanoparticles for Rheumatoid Arthritis. Molecular Therapy, 22(2), 397-408. https://doi.org/10.1038/MT.2013.245

Lee, S. J., Lee, A., Hwang, S. R., Park, J. S., Jang, J., Huh, M. S., .. Kim, K. (2014b). TNF-alpha Gene Silencing Using Polymerized siRNAThiolated Glycol Chitosan Nanoparticles for Rheumatoid Arthritis. Molecular Therapy, 22(2), 397-408. https://doi.org/10.1038/mt.2013.245

Leng, Q., Woodle, M. C., Lu, P. Y., \& Mixson, A. J. (2009). Advances in systemic siRNA delivery. Drugs of the Future, 34(9), 721.

Li, S.-D., Chen, Y.-C., Hackett, M. J., \& Huang, L. (2008). Tumor-targeted delivery of siRNA by self-assembled nanoparticles. Molecular Therapy, 16(1), 163-169.

Li, S.-D., Chono, S., \& Huang, L. (2008). Efficient Oncogene Silencing and Metastasis Inhibition via Systemic Delivery of siRNA. Molecular Therapy, 16(5), 942-946. https://doi.org/10.1038/MT.2008.51

Li, X., Yuan, F. L., Lu, W. G., Zhao, Y. Q., Li, C. W., Li, J. P., \& Xu, R. S. (2010). The role of interleukin-17 in mediating joint destruction in rheumatoid arthritis. Biochem Biophys Res Commun, 397(2), 131-135. https://doi.org/10.1016/j.bbrc.2010.05.111

Liu, X.-M., Quan, L., Tian, J., Laquer, F. C., Ciborowski, P., \& Wang, D. (2010). Syntheses of click PEG- dexamethasone conjugates for the treatment of rheumatoid arthritis. Biomacromolecules, 11(10), 2621-2628.

Liu, X, Zhou, J., Yu, T., Chen, C., Cheng, Q., Sengupta, K., ... Peng, L. (2014). Adaptive amphiphilic dendrimer-based nanoassemblies as robust and versatile siRNA delivery systems. Angew Chem Int Ed Engl, 53(44), 11822-11827. https://doi.org/10.1002/anie.201406764

Liu, Xiaoxuan, Liu, C., Zhou, J., Chen, C., Qu, F., Rossi, J. J., ... Peng, L. (2015). Promoting siRNA delivery via enhanced cellular uptake using an arginine-decorated amphiphilic dendrimer. Nanoscale, 7(9), 3867-3875.

Lorscheider, M., Tsapis, N., Simón-Vázquez, R., Guiblin, N., Ghermani, N., Reynaud, F., ... Fattal, E. (2019). Nanoscale Lipophilic Prodrugs of Dexamethasone with Enhanced Pharmacokinetics. Molecular Pharmaceutics, 16(7), 2999-3010. 
https://doi.org/10.1021/acs.molpharmaceut.9b00237

Lorscheider, M., Tsapis, N., ur-Rehman, M., Gaudin, F., Stolfa, I., Abreu, S., ... Fattal, E. (2019). Dexamethasone palmitate nanoparticles: An efficient treatment for rheumatoid arthritis. Journal of Controlled Release, 296(January), 179-189. https://doi.org/10.1016/j.jconrel.2019.01.015

Lu, Y., Zhang, E. S., Yang, J. H., \& Cao, Z. Q. (2018). Strategies to improve micelle stability for drug delivery. Nano Research, 11(10), 4985-4998. https://doi.org/10.1007/s12274-018-2152-3

Lühder, F., \& Reichardt, H. M. (2017). Novel drug delivery systems tailored for improved administration of glucocorticoids. International Journal of Molecular Sciences, 18(9). https://doi.org/10.3390/ijms18091836

Luo, X., Chen, Y., Lv, G., Zhou, Z., Chen, J., Mo, X., \& Xie, J. (2017). Adenovirus-Mediated Small Interfering RNA Targeting TAK1 Ameliorates Joint Inflammation with Collagen-Induced Arthritis in Mice. Inflammation, 40(3), 894-903. https://doi.org/10.1007/s10753-017-0534-4

Maeda, H. (2010). Tumor-selective delivery of macromolecular drugs via the EPR effect: Background and future prospects. Bioconjugate Chemistry, 21(5), 797-802. https://doi.org/10.1021/bc100070g

Mao, S., Neu, M., Germershaus, O., Merkel, O., Sitterberg, J., Bakowsky, U., \& Kissel, T. (2006). Influence of polyethylene glycol chain length on the physicochemical and biological properties of poly (ethylene imine)-graft-poly (ethylene glycol) block copolymer/SiRNA polyplexes. Bioconjugate Chemistry, 17(5), 1209-1218.

Mateen, S., Zafar, A., Moin, S., Khan, A. Q., \& Zubair, S. (2016). Understanding the role of cytokines in the pathogenesis of rheumatoid arthritis. Clinica Chimica Acta, 455, 161-171. https://doi.org/https://doi.org/10.1016/j.cca.2016.02.010

McDonough, A. K., Curtis, J. R., \& Saag, K. G. (2008). The epidemiology of glucocorticoid-associated adverse events. Current Opinion in Rheumatology, 20(2), 131-137.

McInnes, I. B., \& Schett, G. (2007). Cytokines in the pathogenesis of rheumatoid arthritis. Nature Reviews Immunology, 7(6), 429-442. https://doi.org/10.1038/nri2094

Mehta, G., Scheinman, R. I., Holers, V. M., \& Banda, N. K. (2015). A New Approach for the Treatment of Arthritis in Mice with a Novel Conjugate of an Anti-C5aR1 Antibody and C5 Small Interfering RNA. The Journal of Immunology, 194(11), 5446-5454. https://doi.org/10.4049/jimmunol.1403012

Meister, G., Landthaler, M., Patkaniowska, A., Dorsett, Y., Teng, G., \& Tuschl, T. (2004). Human Argonaute2 Mediates RNA Cleavage Targeted by miRNAs and siRNAs. Molecular Cell, 15(2), 185-197. https://doi.org/10.1016/J.MOLCEL.2004.07.007

Metselaar, J. M., Wauben, M. H. M., Wagenaar-Hilbers, J. P. A., Boerman, O. C., \& Storm, G. (2003). Complete remission of experimental arthritis by joint targeting of glucocorticoids 
with long-circulating liposomes. Arthritis and Rheumatism, 48(7), 2059-2066. https://doi.org/10.1002/art.11140

Mintzer, M. A., \& Grinstaff, M. W. (2011). Biomedical applications of dendrimers: a tutorial. Chemical Society Reviews, 40(1), 173-190.

Morrissey, D. V, Lockridge, J. A., Shaw, L., Blanchard, K., Jensen, K., Breen, W., ... Jadhav, V. (2005). Potent and persistent in vivo anti-HBV activity of chemically modified siRNAs. Nature Biotechnology, 23(8), 1002.

Motoyama, K., Mitsuyasu, R., Akao, C., Abu Hashim II, Sato, N., Tanaka, T., ... Arima, H. (2015). Potential Use of Thioalkylated Mannose-Modified Dendrimer (G3)/alpha-Cyclodextrin Conjugate as an NF-kappa B siRNA Carrier for the Treatment of Fulminant Hepatitis. Molecular Pharmaceutics, 12(9), 3129-3136. https://doi.org/10.1021/mp500814f

Murata, K., Yoshitomi, H., Tanida, S., Ishikawa, M., Nishitani, K., Ito, H., \& Nakamura, T. (2010). Plasma and synovial fluid microRNAs as potential biomarkers of rheumatoid arthritis and osteoarthritis. Arthritis Research \& Therapy, 12(3), R86. https://doi.org/10.1186/ar3013

Neog, M. K., \& Rasool, M. (2018). Targeted delivery of p-coumaric acid encapsulated mannosylated liposomes to the synovial macrophages inhibits osteoclast formation and bone resorption in the rheumatoid arthritis animal model. European Journal of Pharmaceutics and Biopharmaceutics, 133, 162-175. https://doi.org/10.1016/j.ejpb.2018.10.010

Nicolaides, N. C., Galata, Z., Kino, T., Chrousos, G. P., \& Charmandari, E. (2010). The human glucocorticoid receptor: molecular basis of biologic function. Steroids, 75(1), 1-12. https://doi.org/10.1016/j.steroids.2009.09.002

Nimesh, S., Gupta, N., \& Chandra, R. (2011). Cationic polymer based nanocarriers for delivery of therapeutic nucleic acids. Journal of Biomedical Nanotechnology, 7(4), 504-520.

O'Connell, R. M., Rao, D. S., \& Baltimore, D. (2012). microRNA Regulation of Inflammatory Responses. Annual Review of Immunology, 30(1), 295-312. https://doi.org/10.1146/annurev-immunol-020711-075013

O’Mary, H. L., Aldayel, A. M., Valdes, S. A., Naguib, Y. W., Li, X., Salvady, K., \& Cui, Z. (2017). Acid-sensitive sheddable PEGylated, mannose-modified nanoparticles increase the delivery of betamethasone to chronic inflammation sites in a mouse model. Molecular Pharmaceutics, 14(6), 1929-1937.

Ogando, J., Tardáguila, M., Díaz-Alderete, A., Usategui, A., Miranda-Ramos, V., Martínez-Herrera, D. J., ... Mañes, S. (2016). Notch-regulated miR-223 targets the aryl hydrocarbon receptor pathway and increases cytokine production in macrophages from rheumatoid arthritis patients. Scientific Reports, 6(1), 20223. https://doi.org/10.1038/srep20223

Oh, Y.-K., \& Park, T. G. (2009). siRNA delivery systems for cancer treatment. Advanced Drug 
Delivery Reviews, 61(10), 850-862.

Owens, D. E., \& Peppas, N. A. (2006). Opsonization, biodistribution, and pharmacokinetics of polymeric nanoparticles. International Journal of Pharmaceutics, 307(1), 93-102. https://doi.org/10.1016/J.IJPHARM.2005.10.010

Ozbakir, B., Crielaard, B. J., Metselaar, J. M., Storm, G., \& Lammers, T. (2014). Liposomal corticosteroids for the treatment of inflammatory disorders and cancer. Journal of Controlled Release, 190, 624-636. https://doi.org/10.1016/j.jconrel.2014.05.039

Paleolog, E. M. (2002). Angiogenesis in rheumatoid arthritis. Arthritis Research, 4(Suppl 3), S81. https://doi.org/10.1186/ar575

Pandi, P., Jain, A., Kommineni, N., Ionov, M., Bryszewska, M., \& Khan, W. (2018). Dendrimer as a new potential carrier for topical delivery of siRNA: A comparative study of dendriplex vs. lipoplex for delivery of TNF- $\alpha$ siRNA. International Journal of Pharmaceutics, 550(1-2), 240-250. https://doi.org/10.1016/j.ijpharm.2018.08.024

Pap, T., Franz, J. K., Hummel, K. M., Jeisy, E., Gay, R., \& Gay, S. (2000). Activation of synovial fibroblasts in rheumatoid arthritis: lack of Expression of the tumour suppressor PTEN at sites of invasive growth and destruction. Arthritis Res, 2(1), 59-64. https://doi.org/10.1186/ar69

Peer, D., Zhu, P., Carman, C. V, Lieberman, J., \& Shimaoka, M. (2007). Selective gene silencing in activated leukocytes by targeting siRNAs to the integrin lymphocyte function-associated antigen-1. Proceedings of the National Academy of Sciences, 104(10), 4095-4100.

Perise-Barrios, A. J., Jimenez, J. L., Dominguez-Soto, A., de la Mata, F. J., Corbi, A. L., Gomez, R., \& Munoz-Fernandez, M. A. (2014). Carbosilane dendrimers as gene delivery agents for the treatment of HIV infection. Journal of Controlled Release, 184, 51-57. https://doi.org/10.1016/j.jconrel.2014.03.048

Pham, C. T. (2011). Nanotherapeutic approaches for the treatment of rheumatoid arthritis. Wiley Interdiscip Rev Nanomed Nanobiotechnol, 3(6), 607-619. https://doi.org/10.1002/wnan.157

Pirmardvand Chegini, S., Varshosaz, J., \& Taymouri, S. (2018). Recent approaches for targeted drug delivery in rheumatoid arthritis diagnosis and treatment. Artificial Cells, Nanomedicine and Biotechnology, 46(sup2), 502-514. https://doi.org/10.1080/21691401.2018.1460373

Poh, S., Chelvam, V., Ayala-Lopez, W., Putt, K. S., \& Low, P. S. (2018). Selective liposome targeting of folate receptor positive immune cells in inflammatory diseases. Nanomedicine-Nanotechnology Biology and Medicine, 14(3), 1033-1043. https://doi.org/10.1016/j.nano.2018.01.009

Poh, S., Chelvam, V., Kelderhouse, L. E., Ayala-Lopez, W., Vaitilingam, B., Putt, K. S., \& Low, P. S. (2017). Folate-conjugated liposomes target and deliver therapeutics to immune cells in a rat model of rheumatoid arthritis. Nanomedicine, 12(20), 2441-2451. https://doi.org/10.2217/nnm-2017-0166

Posadas, I., Guerra, F. J., \& Ceña, V. (2010). Nonviral vectors for the delivery of small interfering RNAs to the CNS. Nanomedicine, 5(8), 1219-1236. 
Quan, L., Zhang, Y., Crielaard, B. J., Dusad, A., Lele, S. M., Cristianne J. F., R., ... Wang, D. (2013). Nanomedicines for In fl ammatory Arthritis: Head-to-Head Comparison of Glucocorticoid-Containing. ACS Nano, 8(1), 458-466. https://doi.org/10.1117/12.2029490

Quan, L., Zhang, Y., Dusad, A., Ren, K., Purdue, P. E., Goldring, S. R., \& Wang, D. (2016). The Evaluation of the Therapeutic Efficacy and Side Effects of a Macromolecular Dexamethasone Prodrug in the Collagen-Induced Arthritis Mouse Model. Pharmaceutical Research, 33(1), 186-193. https://doi.org/10.1007/s11095-015-1776-1

Rai, M. F., Pan, H., Yan, H., Sandell, L. J., Pham, C. T. N., \& Wickline, S. A. (2019). Applications of RNA interference in the treatment of arthritis. Translational Research: The Journal of Laboratory and Clinical Medicine, 214, 1-16. https://doi.org/10.1016/j.trs1.2019.07.002

Rajasekhar, M., Olsson, A. M., Steel, K. J. A., Georgouli, M., Ranasinghe, U., Brender Read, C., ... Taams, L. S. (2017). MicroRNA-155 contributes to enhanced resistance to apoptosis in monocytes from patients with rheumatoid arthritis. Journal of Autoimmunity, 79, 53-62. https://doi.org/10.1016/j.jaut.2017.01.002

Rauchhaus, U, Kinne, R. W., Pohlers, D., Wiegand, S., Wölfert, A., Gajda, M., ... Panzner, S. (2009). Targeted delivery of liposomal dexamethasone phosphate to the spleen provides a persistent therapeutic effect in rat antigen-induced arthritis. Annals of the Rheumatic Diseases, 68(12), 1933-1934. https://doi.org/10.1136/ard.2009.108985

Rauchhaus, Una, Schwaiger, F. W., \& Panzner, S. (2009). Separating therapeutic efficacy from glucocorticoid side-effects in rodent arthritis using novel, liposomal delivery of dexamethasone phosphate: long-term suppression of arthritis facilitates interval treatment. Arthritis Research \& Therapy, 11(6), R190. https://doi.org/10.1186/ar2889

Rauniyar, V. K., Wu, W., \& Yang, H. (2011). MicroRNAs in autoimmune disease. Autoimmunity Highlights, 2(2), 59-65. https://doi.org/10.1007/s13317-011-0022-z

Rein, P., \& Mueller, R. B. (2017). Treatment with Biologicals in Rheumatoid Arthritis: An Overview. Rheumatology and Therapy, 4(2), 247-261. https://doi.org/10.1007/s40744-017-0073-3

Ren, T., Song, Y. K., Zhang, G., \& Liu, D. (2000). Structural basis of DOTMA for its high intravenous transfection activity in mouse. Gene Therapy, 7(9), 764-768. https://doi.org/10.1038/sj.gt.3301153

Roudier, J. (2000). Association of MHC and rheumatoid arthritis association of RA with HLA-DR4: The role of repertoire selection. Arthritis Research, 2(3), 217-220. https://doi.org/10.1186/ar91

Rupaimoole, R., \& Slack, F. J. (2017). MicroRNA therapeutics: Towards a new era for the management of cancer and other diseases. Nature Reviews Drug Discovery, 16(3), 203-221. https://doi.org/10.1038/nrd.2016.246

Saag, K. G. (1997). Low-dose corticosteroid therapy in rheumatoid arthritis: balancing the evidence. The American Journal of Medicine, 103(6A), 31S-39S. 
Saag, K. G., Koehnke, R., Caldwell, J. R., Brasington, R., Burmeister, L. F., Zimmerman, B., ... Furst, D. E. (1994). Low dose long-term corticosteroid therapy in rheumatoid arthritis: an analysis of serious adverse events. The American Journal of Medicine, 96(2), 115-123.

Saraswathy, M., \& Gong, S. (2014). Recent developments in the co-delivery of siRNA and small molecule anticancer drugs for cancer treatment. Materials Today, 17(6), 298-306.

Sarett, S. M., Nelson, C. E., \& Duvall, C. L. (2015). Technologies for controlled, local delivery of siRNA. Journal of Controlled Release, 218, 94-113.

Scheinman, R. I., Trivedi, R., Vermillion, S., \& Kompella, U. B. (2011). Functionalized STAT1 siRNA nanoparticles regress rheumatoid arthritis in a mouse model. Nanomedicine, 6(10), 1669-1682.

Scott, D. L., Wolfe, F., \& Huizinga, T. W. J. (2010). Rheumatoid arthritis. The Lancet, 376(9746), 1094-1108. https://doi.org/10.1016/S0140-6736(10)60826-4

Shende, P., Ture, N., Gaud, R. S., \& Trotta, F. (2019). Lipid- and polymer-based plexes as therapeutic carriers for bioactive molecules. International Journal of Pharmaceutics, 558, 250-260. https://doi.org/10.1016/j.ijpharm.2018.12.085

Shi, Q., Rondon-Cavanzo, E.-P., Dalla Picola, I. P., Tiera, M. J., Zhang, X., Dai, K., ... Fernandes, J. C. (2018). In vivo therapeutic efficacy of TNF $\alpha$ silencing by folate-PEG-chitosan-DEAE/siRNA nanoparticles in arthritic mice. International Journal of Nanomedicine, 13, 387.

Shuey, D. J., McCallus, D. E., \& Giordano, T. (2002). RNAi: gene-silencing in therapeutic intervention. Drug Discovery Today, 7(20), 1040-1046.

Siebert, S., Tsoukas, A., Robertson, J., \& McInnes, I. (2015). Cytokines as therapeutic targets in rheumatoid arthritis and other inflammatory diseases. Pharmacological Reviews, 67(2), 280-309.

Silva, A., Lopes, C., Lobo, J., \& Amaral, M. (2015). Delivery systems for biopharmaceuticals. Part II: Liposomes, Micelles, Microemulsions and Dendrimers. Current Pharmaceutical Biotechnology, 16(11), 955-965. https://doi.org/10.2174/1389201016666150817094637

Singh, J. A. (2016). Infections With Biologics in Rheumatoid Arthritis and Related Conditions: a Scoping Review of Serious or Hospitalized Infections in Observational Studies. Current Rheumatology Reports, 18(10), 61. https://doi.org/10.1007/s11926-016-0609-5

Singh, R. P., Massachi, I., Manickavel, S., Singh, S., Rao, N. P., Hasan, S., ... Rehimi, H. (2013). The role of miRNA in inflammation and autoimmunity. Autoimmunity Reviews, 12(12), 1160-1165. https://doi.org/10.1016/j.autrev.2013.07.003

Sone, H., Sakauchi, M., Takahashi, A., Suzuki, H., Inoue, N., Iida, K., ... Yamada, N. (2001). Elevated levels of vascular endothelial growth factor in the sera of patients with rheumatoid arthritis correlation with disease activity. Life Sci, 69(16), 1861-1869. Retrieved from https://www.ncbi.nlm.nih.gov/pubmed/11693266

Song, G., Petschauer, J., Madden, A., \& Zamboni, W. (2014). Nanoparticles and the Mononuclear Phagocyte System: Pharmacokinetics and Applications for Inflammatory 
Diseases. Current Rheumatology Reviews, 10(1), 22-34. https://doi.org/10.2174/1573403X10666140914160554

Song, J.-J., Smith, S. K., Hannon, G. J., \& Joshua-Tor, L. (2004). Crystal Structure of Argonaute and Its Implications for RISC Slicer Activity. Science, 305(5689), 1434-1437. https://doi.org/10.1126/SCIENCE.1102514

Song, J., Chen, Y., Jiang, S., Yang, K., Li, X., Zhao, X., ... Yuan, W. (2016). Efficient and non-toxic biological response carrier delivering TNF- $\alpha$ shRNA for gene silencing in a murine model of rheumatoid arthritis. Frontiers in Immunology, 7, 305.

Song, Y. W., \& Kang, E. H. (2009). Autoantibodies in rheumatoid arthritis: rheumatoid factors and anticitrullinated protein antibodies. QJM: An International Journal of Medicine, 103(3), 139-146. https://doi.org/10.1093/qjmed/hcp165

Sørensen, D. R., Leirdal, M., \& Sioud, M. (2003). Gene silencing by systemic delivery of synthetic siRNAs in adult mice. Journal of Molecular Biology, 327(4), 761-766.

Stanczyk, J., Leslie Pedrioli, D. M., Brentano, F., Sanchez-Pernaute, O., Kolling, C., Gay, R. E., ... Kyburz, D. (2008). Altered expression of microRNA in synovial fibroblasts and synovial tissue in rheumatoid arthritis. Arthritis and Rheumatism, 58(4), 1001-1009. https://doi.org/10.1002/art.23386

Stenvang, J., Petri, A., Lindow, M., Obad, S., \& Kauppinen, S. (2012). Inhibition of microRNA function by antimiR oligonucleotides. Silence, $3(1), \quad 1$. https://doi.org/10.1186/1758-907X-3-1

Tarrant, T. K., \& Patel, D. D. (2006). Chemokines and leukocyte trafficking in rheumatoid arthritis. Pathophysiology, 13(1), 1-14. https://doi.org/10.1016/j.pathophys.2005.11.001

Thomas, M., \& Klibanov, A. M. (2002). Enhancing polyethylenimine's delivery of plasmid DNA into mammalian cells. Proceedings of the National Academy of Sciences, 99(23), $14640-14645$.

Tobon, G. J., Youinou, P., \& Saraux, A. (2010). The environment, geo-epidemiology, and autoimmune disease: Rheumatoid arthritis. Autoimmun Rev, 9(5), A288-92. https://doi.org/10.1016/j.autrev.2009.11.019

van den Hoven, J. M., Hofkens, W., Wauben, M. H. M., Wagenaar-Hilbers, J. P. A., Beijnen, J. H., Nuijen, B., ... Storm, G. (2011). Optimizing the therapeutic index of liposomal glucocorticoids in experimental arthritis. International Journal of Pharmaceutics, 416(2), 471-477. https://doi.org/10.1016/J.IJPHARM.2011.03.025

van Drongelen, V., \& Holoshitz, J. (2017). Human Leukocyte Antigen-Disease Associations in Rheumatoid Arthritis. Rheumatic Diseases Clinics of North America, 43(3), 363-376. https://doi.org/10.1016/j.rdc.2017.04.003

van Laar, M., Pergolizzi, J. V, Mellinghoff, H.-U., Merchante, I. M., Nalamachu, S., O'Brien, J., ... Raffa, R. B. (2012). Pain treatment in arthritis-related pain: beyond NSAIDs. The Open Rheumatology Journal, 6, 320-330. https://doi.org/10.2174/1874312901206010320

Vandevyver, S., Dejager, L., \& Libert, C. (2012). On the trail of the glucocorticoid receptor: into 
the nucleus and back. Traffic (Copenhagen, Denmark), 13(3), 364-374. https://doi.org/10.1111/j.1600-0854.2011.01288.x

Wada, M., Kawahito, Y., Kimura, S., Kohno, M., Ishino, H., Kimura, M., ... Yoshikawa, T. (2007). siRNA targeting PLK-1 induces apoptosis of synoviocytes in rheumatoid arthritis. Biochemical and Biophysical Research Communications, 357(2), 353-359. https://doi.org/10.1016/j.bbrc.2007.03.190

Wang, D., Miller, S. C., Liu, X. M., Anderson, B., Wang, X. S., \& Goldring, S. R. (2007). Novel dexamethasone-HPMA copolymer conjugate and its potential application in treatment of rheumatoid arthritis. Arthritis Research \& Therapy, 9(1), 9. https://doi.org/10.1186/ar2106

Wang, Q, \& Sun, X. (2017). Recent advances in nanomedicines for the treatment of rheumatoid arthritis. Biomater Sci, 5(8), 1407-1420. https://doi.org/10.1039/c7bm00254h

Wang, Qin, Jiang, H., Li, Y., Chen, W., Li, H., Peng, K., ... Sun, X. (2017). Targeting NF-kB signaling with polymeric hybrid micelles that co-deliver siRNA and dexamethasone for $\begin{array}{lllr}\text { arthritis therapy. } & \text { Biomaterials, } & 122,22 .\end{array}$ https://doi.org/10.1016/j.biomaterials.2017.01.008

Wang, Qin, Jiang, J., Chen, W., Jiang, H., Zhang, Z., \& Sun, X. (2016). Targeted delivery of low-dose dexamethasone using PCL-PEG micelles for effective treatment of rheumatoid arthritis. Journal of Controlled Release, 230, 64-72. https://doi.org/10.1016/j.jconrel.2016.03.035

Wang, Qin, Li, Y., Chen, X., Jiang, H., Zhang, Z., \& Sun, X. (2019). Optimized in vivo performance of acid-liable micelles for the treatment of rheumatoid arthritis by one single injection. Nano Research, 12(2), 421-428. https://doi.org/10.1007/s12274-018-2233-3

Wang, X., Wang, X., Sun, J., \& Fu, S. (2018). An enhanced RRM2 siRNA delivery to rheumatoid arthritis fibroblast-like synoviocytes through a liposome- protamine-DNA-siRNA complex with cell permeable peptides. International Journal of Molecular Medicine, 42(5), 2393-2402.

Wang, Z., Chu, X., Li, N., Fu, L., Gu, H., \& Zhang, N. (2020). Engineered DNA nanodrugs alleviate inflammation in inflammatory arthritis. International Journal of Pharmaceutics, 577(January). https://doi.org/10.1016/j.ijpharm.2020.119047

Wei, X., Li, F., Zhao, G., Chhonker, Y. S., Averill, C., Galdamez, J., ... Wang, D. (2017). Pharmacokinetic and Biodistribution Studies of HPMA Copolymer Conjugates in an Aseptic Implant Loosening Mouse Model. Molecular Pharmaceutics, 14(5), 1418-1428.

Whitehead, K. A., Langer, R., \& Anderson, D. G. (2009). Knocking down barriers: advances in siRNA delivery. Nature Reviews Drug Discovery, 8(2), 129.

Wilson, D. R., Zhang, N., Silvers, A. L., Forstner, M. B., \& Bader, R. A. (2014). Synthesis and evaluation of cyclosporine A-loaded polysialic acid-polycaprolactone micelles for rheumatoid arthritis. European Journal of Pharmaceutical Sciences, 51, 146-156.

Wu, Z.-W., Chien, C.-T., Liu, C.-Y., Yan, J.-Y., \& Lin, S.-Y. (2012). Recent progress in copolymer-mediated siRNA delivery. Journal of Drug Targeting, 20(7), 551-560. 
Xiao, S., Tang, Y., Lv, Z., Lin, Y., \& Chen, L. (2019). Nanomedicine - advantages for their use in rheumatoid arthritis theranostics. Journal of Controlled Release. https://doi.org/10.1016/j.jconrel.2019.11.008

$\mathrm{Xu}, \mathrm{C} .$, \& Wang, J. (2015). Delivery systems for siRNA drug development in cancer therapy. Asian Journal of Pharmaceutical Sciences, 10(1), 1-12.

Yang, C., Gao, S., \& Kjems, J. (2014). Folic acid conjugated chitosan for targeted delivery of siRNA to activated macrophages in vitro and in vivo. J. Mater. Chem. B, 2(48), 8608-8615. https://doi.org/10.1039/C4TB01374C

Yang, M., Feng, X., Ding, J., Chang, F., \& Chen, X. (2017). Nanotherapeutics relieve rheumatoid arthritis. Journal of Controlled Release, 252, 108-124. https://doi.org/10.1016/j.jconrel.2017.02.032

Yasuda, M., Gan, L., Chen, B., Kadirvel, S., Yu, C., Phillips, J. D., ... Querbes, W. (2014). RNAi-mediated silencing of hepatic Alas1 effectively prevents and treats the induced acute attacks in acute intermittent porphyria mice. Proceedings of the National Academy of Sciences, 111(21), 7777-7782.

Yin, H., Kanasty, R. L., Eltoukhy, A. A., Vegas, A. J., Dorkin, J. R., \& Anderson, D. G. (2014). Non-viral vectors for gene-based therapy. Nature Reviews Genetics, 15(8), 541-555.

Yu, C., Zhang, X., Sun, X., long, C., Sun, F., Liu, J., ... Teng, L. (2018). Ketoprofen and MicroRNA-124 Co-loaded poly (lactic-co-glycolic acid) microspheres inhibit progression of Adjuvant-induced arthritis in rats. International Journal of Pharmaceutics, 552(1-2), 148-153. https://doi.org/10.1016/J.IJPHARM.2018.09.063

Yu, T., Liu, X., Bolcato-Bellemin, A. L., Wang, Y., Liu, C., Erbacher, P., ... Peng, L. (2012). An amphiphilic dendrimer for effective delivery of small interfering RNA and gene silencing in vitro and in vivo. Angew Chem Int Ed Engl, 51(34), 8478-8484. https://doi.org/10.1002/anie.201203920

Zhang, Pengfei, Wang, H., Luo, X., Liu, H., Lu, B., Li, T., ... Sun, X. (2018). MicroRNA-155 Inhibits Polarization of Macrophages to M2-Type and Suppresses Choroidal Neovascularization. $\quad$ Inflammation, $\quad 41(1), \quad 143-153$. https://doi.org/10.1007/s10753-017-0672-8

Zhang, Penghui, An, K., Duan, X., Xu, H., Li, F., \& Xu, F. (2018). Recent advances in siRNA delivery for cancer therapy using smart nanocarriers. Drug Discovery Today, 23(4), 900-911.

Zhang, S., Zhao, B., Jiang, H., Wang, B., \& Ma, B. (2007). Cationic lipids and polymers mediated vectors for delivery of siRNA. Journal of Controlled Release, 123(1), 1-10. https://doi.org/10.1016/j.jconrel.2007.07.016

Zhao, G., \& Zhang, H. (2018). Notch-1 siRNA and Methotrexate towards a Multifunctional Approach in Rhematoid Arthritis Management: a Nanomedicine Approach. Pharmaceutical Research, 35(6), 123. https://doi.org/10.1007/s11095-018-2401-x

Zhou, H., Yan, H., Pan, H., Hou, K. K., Akk, A., Springer, L. E., .. Pham, C. T. N. (2014). 
Peptide-siRNA nanocomplexes targeting NF- $\mathrm{kB}$ subunit $\mathrm{p} 65$ suppress nascent experimental arthritis. The Journal of Clinical Investigation, 124(10), 4363-4374. https://doi.org/10.1172/JCI75673 